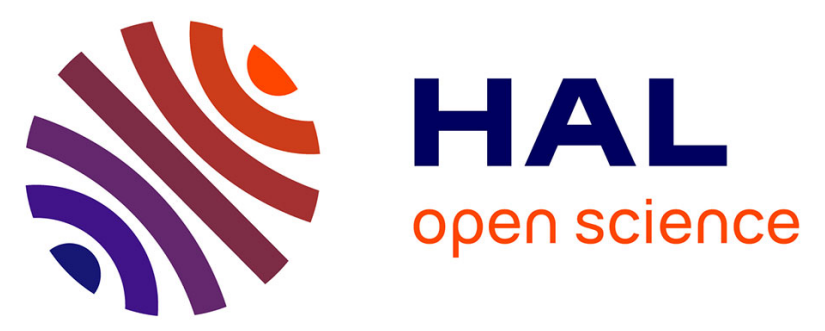

\title{
A combined experimental and theoretical study of the polar $[3+2]$ cycloaddition of electrophilically activated carbonyl ylides with aldehydes and imines
}

Ghenia Bentabed-Ababsa, Aicha Derdour, Thierry Roisnel, José A. Saez, Patricia Pérez, Edouardo Chamorro, Luis .R. Domingo, Florence Mongin

\section{To cite this version:}

Ghenia Bentabed-Ababsa, Aicha Derdour, Thierry Roisnel, José A. Saez, Patricia Pérez, et al.. A combined experimental and theoretical study of the polar [3+2] cycloaddition of electrophilically activated carbonyl ylides with aldehydes and imines. Journal of Organic Chemistry, 2009, 74 (5), pp.2120-2133. 10.1021/jo8027104 . hal-00784590

\author{
HAL Id: hal-00784590 \\ https://hal.science/hal-00784590
}

Submitted on 4 Feb 2013

HAL is a multi-disciplinary open access archive for the deposit and dissemination of scientific research documents, whether they are published or not. The documents may come from teaching and research institutions in France or abroad, or from public or private research centers.
L'archive ouverte pluridisciplinaire HAL, est destinée au dépôt et à la diffusion de documents scientifiques de niveau recherche, publiés ou non, émanant des établissements d'enseignement et de recherche français ou étrangers, des laboratoires publics ou privés. 


\section{A combined experimental and theoretical study of the polar}

\section{[3+2] cycloaddition of electrophilically activated carbonyl ylides}

\section{with aldehydes and imines}

Ghenia Bentabed-Ababsa, ${ }^{\dagger \ddagger}$ Aicha Derdour, ${ }^{\ddagger}$ Thierry Roisnel, ${ }^{\natural}$ Jose A. Sáez, ${ }^{\S}$ Patricia Pérez, ${ }^{\ddagger}$ Eduardo Chamorro, ${ }^{¥}$ Luis R. Domingo ${ }^{*}, \S$ and Florence Mongin* ${ }^{* \dagger}$

Chimie et Photonique Moléculaires, UMR 6510 CNRS, Université de Rennes 1, Bâtiment 10A, Case 1003, Campus Scientifique de Beaulieu, 35042 Rennes, France, Laboratoire de Synthèse Organique Appliquée, Faculté des Sciences de l'Université, BP 1524 Es-Senia, Oran 31000, Algeria, Centre de Diffractométrie X, Sciences Chimiques de Rennes, UMR 6226 CNRS, Université de Rennes 1, Bâtiment 10B, Campus Scientifique de Beaulieu, F-35042 Rennes Cedex, France, Departamento de Química Orgánica, Universidad de Valencia, Dr. Moliner 50, 46100 Burjassot, Valencia, Spain, Universidad Andres Bello, Facultad de Ecología y Recursos Naturales, Departamento de Ciencias Químicas, Laboratorio de Química Teórica, Av. República 275, 8370146 Santiago, Chile. domingo@utopia.uv.es, florence.mongin@univ-rennes1.fr

RECEIVED DATE (to be automatically inserted after your manuscript is accepted if required according to the journal that you are submitting your paper to)

${ }^{\dagger}$ Rennes 1.

$\ddagger$ Oran.

" Rennes 1 (CDIFX).

$\S$ Valencia.

¥ Andres Bello.

* Corresponding authors. Fax: +34 963544328 (L.R.D.), +33 223236955 (F.M.). 


\title{
Table of Contents (TOC) graphic
}

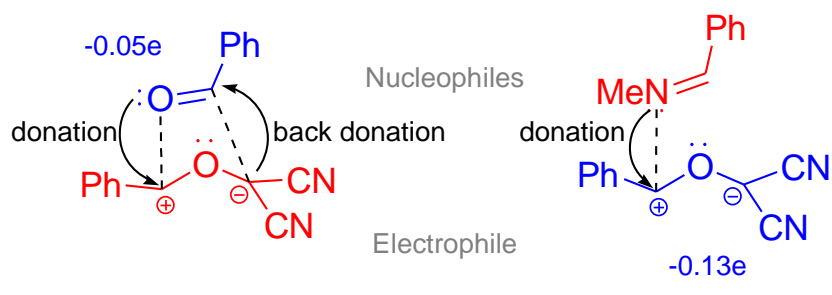

concerted TS

TSo1t

nonconcerted TS

TSn1t

Reverse net CT at the reactions with aldehydes

\begin{abstract}
Numerous 2,5-diaryl-1,3-dioxolane-4,4-dicarbonitriles and 2,4-diphenyl-1,3-oxazolidine-5,5dicarbonitriles have been synthesized by [3+2] cycloaddition reactions between carbonyl ylides generated from epoxides, and aldehydes or imines. In contrast to the use of aldehydes $(3,4,5-$ trimethoxybenzaldehyde, piperonal, 1-naphthaldehyde, indole-3-carboxaldehyde, furan-2carboxaldehyde and thiophene-2-carboxaldehyde), the reactions performed with imines $(N$ (phenylmethylene)methanamine, $N$-(1,3-benzodioxol-5-ylmethylene)propylamine, $N$-(1,3-benzodioxol5-ylmethylene)butylamine and $\quad N$-(1,3-benzodioxol-5-ylmethylene)benzylamine) proceed diastereoselectively. The effect of microwave irradiation on the outcome of the reaction was studied. The mechanism of these [3+2] cycloaddition reactions has been theoretically investigated using DFT methods. These cycloadditions, which have one-step mechanisms, consist of the nucleophilic attack of the aldehyde oxygen or imine nitrogen on the carbonyl ylide. For the reaction with aldehydes, a back donation effect is responsible for the unexpected reverse charge transfer found at the transition structure. The analysis of the reactivity indices indicates that the large electrophilic character of the carbonyl ylides induces them to act as strong electrophiles in these polar [3+2] cycloaddition reactions.
\end{abstract}




\section{Introduction}

Cycloaddition reactions are fundamental synthetic processes, with both synthetic and mechanistic interest in organic chemistry. Among them, 1,3-dipolar cycloadditions, the general concept of which was introduced by Huisgen and co-workers in the $1960 \mathrm{~s},{ }^{1}$ are versatile tools for building fivemembered heterocycles. ${ }^{2}$

The 1,3-dioxolane ${ }^{3}$ and oxazolidine ${ }^{4}$ moieties represent important skeletons present in molecules endowed with biological activities. Derivatives can be synthesized by reaction of carbonyl ylides, generated by thermal electrocyclic ring opening of epoxides, with $\pi$-bonds of aldehydes ${ }^{5}$ and imines. ${ }^{6}$

Current understanding of the underlying principles in reactions such as 1,3-dipolar cycloaddition has grown from a fruitful interplay between theory and experiment. ${ }^{2}$ Through a recent study of the [3+2] cycloaddition reaction between carbonyl ylides and ketones in order to synthesize spirocyclic dioxolane indolinones, ${ }^{7}$ we have embarked on theoretical calculations using DFT methods to depict the mechanism of these reactions using carbonyl ylides generated from epoxides. These reactions are domino processes that comprise two consecutive reactions (see Scheme 1). ${ }^{7}$ The first one is the thermal ring opening of the epoxide 1a to yield the carbonyl ylide intermediate CYa, whereas the second reaction is a concerted [3+2] cycloaddition of CYa with the ketone function of $N$-methylisatin to yield the final [3+2] spirocycloadducts SCAa. The activation energy associated with the thermal ring opening of the epoxide 1a, $26.9 \mathrm{kcal} / \mathrm{mol}$, proved to be slightly higher than that associated with the thermal opening of the cyclopropane ring on the 2,2-dimethoxy-3,3-dicyanospiro[cyclopropane-1,9'$[9 H]$ fluorene recently reported by Warkentin, $24.4 \mathrm{kcal} / \mathrm{mol} .^{8}$ However, the formation of the corresponding carbonyl ylide CYa was lesser endothermic, $11.7 \mathrm{kcal} / \mathrm{mol}$, that the corresponding zwitterion intermediate, $22.8 \mathrm{kcal} / \mathrm{mol}$. Interestingly, the zwitterion proposed by Warkentin was captured by benzaldehyde to yield a formally [3+2] cycloadduct, which showed the same regioselectivity than that found on the reaction of CYa with isatin. 
In spite of the cycloaddition has a lower activation energy than that for the opening of the epoxide, the large endothermic character of the formation of the intermediate CYa together with the bimolecular nature of the cycloaddition, make this reaction to be the rate-limiting step of the overall domino process. The energetic results indicated that the [3+2] cycloaddition reaction present a poor stereoselectivity and a large regio- and chemoselectivity, in agreement with the experimental results. The most favorable regioisomeric channels were associated with the nucleophilic attack of the isatin carbonyl oxygen atom to the phenyl substituted carbon atom of the carbonyl ylide CYa. The larger electrophilicity of the carbonyl ylide CYa, $\omega=4.29 \mathrm{eV}$, with respect to $N$-methylisatin, $\omega=2.66 \mathrm{eV}$, allowed us to explain the nucleophilic attack of the carbonyl oxygen of the isatin to the phenyl substituted carbon atom of CYa. However, a charge transfer (CT) analysis at the transition state structures (TSs) showed a slight net CT to the ketone framework.

SCHEME 1. Thermal Ring Opening of the Epoxide 1a, and Cycloaddition Reaction between CYa and $N$-methylisatin.

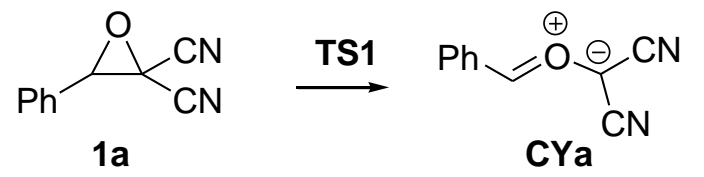<smiles>Cn1c(=O)c(=O)c2ccccc2n1C</smiles>

If reactions between carbonyl ylides, generated by thermal electrocyclic ring opening of epoxides, with $\pi$-bonds of aldehydes ${ }^{5, b}$ and imines ${ }^{6}$ have previously been described with similar regiospecificity and stereoselectivity, the identification of the cis and trans cycloadducts products has not been studied unequivocally. Here we describe similar syntheses, ${ }^{9}$ but most of all the structural analysis of the cycloadducts as well as their formation mechanism. 
The discrepancy between the electrophile/nucleophile interaction and the CT observed at the TSs of the cycloaddition of the carbonyl ylide CYa with $N$-methylisatin has encouraged us to perform subsequent studies on the mechanism of these [3+2] cycloaddition reactions.

\section{Results and Discussion}

\section{Synthetic Aspects}

Reactions were first carried out between 2,2-dicyano-3-(4-substituted)phenyloxiranes $\mathbf{1 a - c ^ { 1 0 }}$ and benzaldehydes 2 (1 molar equivalent) in order to get 2,5-diphenyl-1,3-dioxolane-4,4-dicarbonitriles (Table 1). The conversion to the derivatives 3-5 using 3,4,5-trimethoxybenzaldehyde (2a) was monitored by NMR, and showed that the reactions carried out in refluxing toluene were completed after 35-68 h, depending on the $\mathrm{R}^{1}$ group on the epoxide $\mathbf{1}$. The cis products $\mathbf{3 a - 5 a}$ were isolated from the crude mixture by recrystallization from petrol/ $\mathrm{Et}_{2} \mathrm{O}$ in yields ranging from 40 to $52 \%$, and identified by NMR. NOESY, HMBC and HMQC sequences performed on $\left(\mathrm{CD}_{3}\right)_{2} \mathrm{CO}$ solutions which allowed for the assignments of the ${ }^{1} \mathrm{H}$ and ${ }^{13} \mathrm{C}$ NMR signals. The NOESY experiment showed the relationship between H2 (singlets at 6.59, 6.57 and 6.53 ppm for 3a, 4a and 5a, respectively) and H2'-H6' (at 7.80, 7.74 and 7.68 ppm), and between H2 and H5 (singlets at 6.04, 6.00 and 5.99 ppm) (see Table 1, a). Cis 5a was then identified unequivocally by X-ray structure analysis. The trans compounds $\mathbf{3 b}$-5b were identified using ${ }^{1} \mathrm{H}$ NMR spectra of enriched fractions. The diastereoisomeric ratios were determined from ${ }^{1} \mathrm{H}$ NMR spectra of the crude mixtures. The cis products predominate over the trans with about 3 to $1(\mathbf{a}: \mathbf{b})$ ratios.

A rising number of articles have advocated the use of microwave technology in organic synthesis. Long reaction times often required for cycloaddition reactions could generally be reduced using this technique. ${ }^{11}$ Thus, several experiments were performed using microwave irradiation at various powers and irradiation times. ${ }^{12}$ The best conditions were obtained without solvent (power: $60 \mathrm{~W}$ ), with significant reduction of reaction times ( $45 \mathrm{~min}$ instead of $35 \mathrm{~h}$ for $3\left(\mathrm{R}^{1}=\mathrm{H}\right), 40 \mathrm{~min}$ instead of $68 \mathrm{~h}$ for 
$4\left(\mathrm{R}^{1}=\mathrm{Cl}\right)$, and $35 \mathrm{~min}$ instead of $45 \mathrm{~h}$ for $\left.5\left(\mathrm{R}^{1}=\mathrm{OMe}\right)\right)$ and similar $\mathbf{a}: \mathbf{b}$ ratios $(68 / 32$ instead of $77 / 23$ for $3\left(\mathrm{R}^{1}=\mathrm{H}\right), 71 / 29$ instead of $72 / 28$ for $\mathbf{4}\left(\mathrm{R}^{1}=\mathrm{Cl}\right)$, and $70 / 30$ instead of $68 / 32$ for $\left.\mathbf{5}\left(\mathrm{R}^{1}=\mathrm{OMe}\right)\right)$ in comparison to reaction in toluene at reflux ${ }^{13}$ (Table 1, Entries 1-3).

Replacing 3,4,5-trimethoxybenzaldehyde (2a) by piperonal (2b) slightly disfavored the formation of the $c$ is compounds $\mathbf{6 a}$ and $7 \mathbf{a}$ over the trans $\mathbf{6 b}$ and $\mathbf{7 b}$ (average $\mathbf{a}: \mathbf{b}$ ratios of $62 / 38$ for $\mathbf{6}$ against $72 / 28$ for $3\left(\mathrm{R}^{1}=\mathrm{H}\right)$, and $60 / 40$ for 7 against $71 / 29$ for $\left.4\left(\mathrm{R}^{1}=\mathrm{Cl}\right)\right)$ whereas the same ratio $(69 / 31)$ was obtained for $\mathbf{8}$ and $5\left(\mathrm{R}^{1}=\mathrm{OMe}\right)$ (Entries 4-6). The trans $\mathbf{7 b}$ and $\mathbf{8 b}$ could only be identified using ${ }^{1} \mathrm{H}$ NMR spectra of enriched fractions, but crystals of $\mathbf{6 b}$ suitable for X-ray structure analysis were obtained.

TABLE 1. Reactions between Epoxides 1 and Benzaldehydes 2

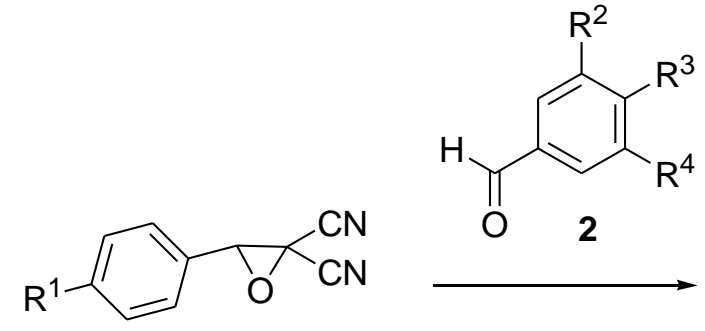

1

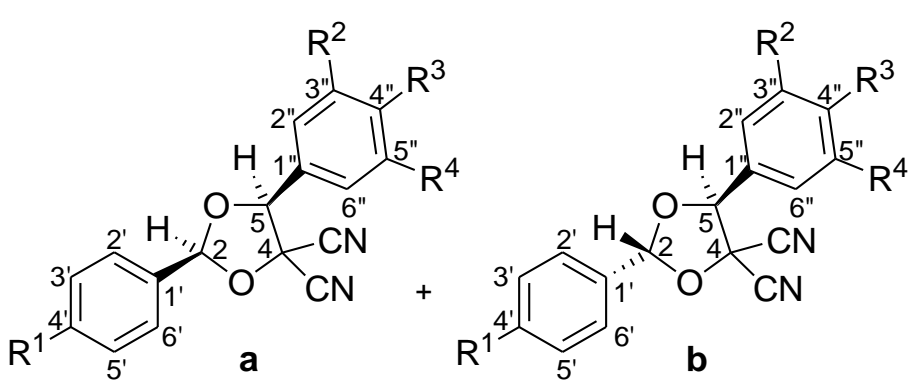

\begin{tabular}{|c|c|c|c|c|c|c|}
\hline entry & $\mathrm{R}^{1}(\mathbf{1})$ & aldehyde & $\mathbf{a}: \mathbf{b}$ & conditions & $\mathbf{a}: \mathbf{b}$ ratio $^{a}$ & isolated product, yield \\
\hline \multirow[t]{2}{*}{1} & \multirow[t]{2}{*}{$\mathrm{H}(\mathbf{1 a})$} & & 3a:3b & toluene, reflux, $35 \mathrm{~h}$ & $77 / 23$ & $\mathbf{3 a}, 40 \%$ \\
\hline & & & & $\mathrm{MW},{ }^{b} 60 \mathrm{~W}, 120^{\circ} \mathrm{C}, 45 \mathrm{~min}$ & $68 / 32$ & $\mathbf{3 a}, 49 \%$ \\
\hline \multirow[t]{2}{*}{2} & \multirow[t]{2}{*}{$\mathrm{Cl}(\mathbf{1 b})$} & & $4 a: 4 b$ & toluene, reflux, $68 \mathrm{~h}$ & $72 / 28$ & $\mathbf{4 a}, 42 \%$ \\
\hline & & & & $\mathrm{MW}, b 0 \mathrm{~W}, 120^{\circ} \mathrm{C}, 40 \mathrm{~min}$ & $71 / 29$ & $4 a, 45 \%$ \\
\hline \multirow[t]{2}{*}{3} & \multirow[t]{2}{*}{ OMe (1c) } & & $5 a: 5 b$ & toluene, reflux, $45 \mathrm{~h}$ & $68 / 32$ & 5a, $52 \%$ \\
\hline & & & & $\mathrm{MW},{ }^{b} 60 \mathrm{~W}, 80^{\circ} \mathrm{C}, 35 \mathrm{~min}$ & $70 / 30$ & $5 \mathbf{a}, 55 \%$ \\
\hline \multirow[t]{2}{*}{4} & \multirow[t]{2}{*}{$\mathrm{H}(\mathbf{1} \mathbf{a})$} & & $6 a: 6 b$ & toluene, reflux, $45 \mathrm{~h}$ & $58 / 42$ & $\mathbf{6 a}, 31 \%$ \\
\hline & & & & $\mathrm{MW}, b 0 \mathrm{~W}, 120^{\circ} \mathrm{C}, 40 \mathrm{~min}$ & $66 / 34$ & $\mathbf{6 a}, 25 \%$ \\
\hline \multirow[t]{2}{*}{5} & \multirow[t]{2}{*}{$\mathrm{Cl}(\mathbf{1 b})$} & & $7 a: 7 b$ & toluene, reflux, $72 \mathrm{~h}$ & $60 / 40$ & $7 a, 28 \%$ \\
\hline & & & & $\mathrm{MW},{ }^{b} 60 \mathrm{~W}, 120^{\circ} \mathrm{C}, 40 \mathrm{~min}$ & $60 / 40$ & $7 \mathbf{a}, 39 \%$ \\
\hline \multirow[t]{2}{*}{6} & \multirow[t]{2}{*}{ OMe (1c) } & 20 & $8 a: 8 b$ & toluene, reflux, $48 \mathrm{~h}$ & $71 / 29$ & $8 a, 54 \%$ \\
\hline & & & & $\mathrm{MW},{ }^{b} 60 \mathrm{~W}, 80^{\circ} \mathrm{C}, 30 \mathrm{~min}$ & $67 / 33$ & $\mathbf{8 a}, 40 \%$ \\
\hline
\end{tabular}


The $c$ is products $\mathbf{6 a - 8 a}$ were isolated from the crude mixture by recrystallization from petrol/ $\mathrm{Et}_{2} \mathrm{O}$ in moderate to medium yields. Their structures were elucidated as for compounds 3a-5a using NMR experiments, and confirmed by X-ray analysis.

In order to reach differently 5-substituted 2-(4-substituted phenyl)-1,3-dioxolane-4,4-dicarbonitriles, reactions were performed with 1-naphthaldehyde (9), indole-3-carboxaldehyde (10), furan-2carboxaldehyde (11) and thiophene-2-carboxaldehyde (12) (1 molar equivalent) (Table 2). The reactions were completed in refluxing toluene after reaction times of 35-84 h, depending on both the $\mathrm{R}$ group on the epoxide $\mathbf{1}$ and the nature of the aldehyde. The reactions were also carried out under microwave irradiation, allowing reaction times to be reduced from 54-84 h to 30-45 min.

The cis products 13a-15a proved to be favored over the trans for the reactions carried out between 2,2-dicyano-3-(4-substituted)phenyloxiranes $\mathbf{1} \mathbf{a}_{-\mathbf{c}^{10}}$ and 1-naphthaldehyde (9). They were isolated from the crude mixtures by column chromatography over silica gel in yields ranging from 27 to $55 \%$, and identified by NMR. NOESY, HMBC and HMQC sequences performed on the racemic 14a allowed the assignments of the main ${ }^{1} \mathrm{H}$ and ${ }^{13} \mathrm{C}$ signals. The proximity between $\mathrm{H} 2$ and $\mathrm{H} 5$, in accordance with a cis stereochemistry, was shown by conducting the NOESY experiment in $\mathrm{CDCl}_{3}$, after assignment of the singlets at 6.38 and $6.48 \mathrm{ppm}^{14}$ to $\mathrm{H} 2$ (correlation between $\mathrm{H} 2$ and $\mathrm{H} 2$ '-H6') and H5 (correlation between H5 and H2”), respectively (see Table 2, a). After identification of the trans compounds 13b15b from ${ }^{1} \mathrm{H}$ NMR spectra of the crude mixtures, the diastereoisomeric ratios were calculated using the integration. The $\mathbf{a}: \mathbf{b}$ ratio is about $63 / 37$ when $\mathrm{R}=\mathrm{H}$, against $71 / 29$ when $\mathrm{R}=\mathrm{Cl}$ and OMe, and is slightly favored using classical heating conditions (Entries 1-3).

The reactions carried out under classical heating conditions between 2,2-dicyano-3-(4substituted)phenyloxiranes $\mathbf{1 a - c ^ { 1 0 }}$ and indole-3-carboxaldehyde (10) resulted in different diastereoisomeric ratios than using 1-naphthaldehyde (9). Indeed, 50/50 (16, R = H), 43/57 (17, $\mathrm{R}=\mathrm{Cl})$ and $84 / 16(18, \mathrm{R}=\mathrm{OMe})$ were obtained as cis/trans ratios using the heterocyclic aldehyde against 65/35 (13, R = H), 75/25 (14, R= Cl) and 76/24 (15, $\mathrm{R}=\mathrm{OMe})$ for the non-heterocyclic one. Recourse 
to microwave irradiation favors the formation of $\mathbf{1 6 a - 1 7 a}$ over $\mathbf{1 6 b}-\mathbf{1 7 b}$, but disfavors the formation of 18a over 18b (Entries 4-6). The cis products were isolated from the crude mixture by column chromatography over silica gel in 30 to $46 \%$ yields, and were identified by NMR as before, by identifying a correlation relation between $\mathrm{H} 2$ and $\mathrm{H} 5$ (see Table 2, a). The structure of 17a was confirmed by X-ray analysis of crystals obtained by slowly evaporating an acetone solution. The products 16b-17b were identified using ${ }^{1} \mathrm{H}$ and ${ }^{13} \mathrm{C}$ NMR spectra of enriched fractions, and $\mathbf{1 8 b}$ from the ${ }^{1} \mathrm{H}$ NMR spectra of the crude mixture.

TABLE 2. Reactions between Epoxides 1 and Aldehydes 9-12
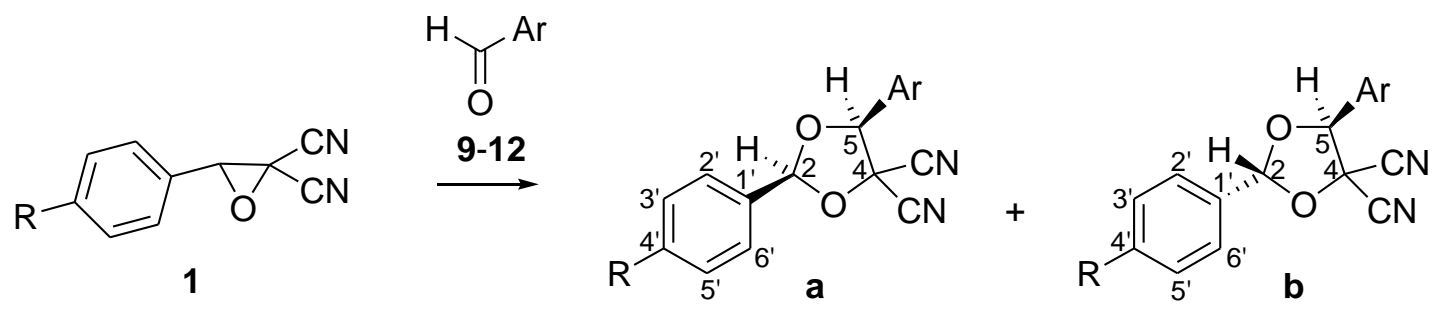

\begin{tabular}{|c|c|c|c|c|c|c|}
\hline entry & $\mathrm{R}(\mathbf{1})$ & aldehyde & $\mathbf{a}: \mathbf{b}$ & conditions & $\mathbf{a}: \mathbf{b}$ ratio $^{a}$ & isolated product(s), yield(s) \\
\hline \multirow[t]{2}{*}{1} & \multirow[t]{2}{*}{$\mathrm{H}(\mathbf{1 a})$} & & \multirow[t]{2}{*}{$13 a: 13 b$} & toluene, reflux, $80 \mathrm{~h}$ & $65 / 35$ & $13 a, 27 \%$ \\
\hline & & & & $\mathrm{MW},{ }^{b} 90 \mathrm{~W}, 120^{\circ} \mathrm{C}, 40 \mathrm{~min}$ & $62 / 38$ & $\mathbf{1 3 a}, 35 \%$ \\
\hline \multirow[t]{2}{*}{2} & \multirow[t]{2}{*}{$\mathrm{Cl}(\mathbf{1 b})$} & \multirow{4}{*}{9} & \multirow[t]{2}{*}{$14 a: 14 b$} & toluene, reflux, $72 \mathrm{~h}$ & $75 / 25$ & $\mathbf{1 4 a}, 32 \%$ \\
\hline & & & & $\mathrm{MW}^{b}, 90 \mathrm{~W}, 120^{\circ} \mathrm{C}, 40 \mathrm{~min}$ & $63 / 37$ & $\mathbf{1 4 a}, 42 \%$ \\
\hline \multirow[t]{2}{*}{3} & \multirow[t]{2}{*}{ OMe (1c) } & & \multirow[t]{2}{*}{$15 a: 15 b$} & toluene, reflux, $57 \mathrm{~h}$ & $76 / 24$ & $\mathbf{1 5 a}, 48 \%$ \\
\hline & & & & $\mathrm{MW},{ }^{b} 90 \mathrm{~W}, 80^{\circ} \mathrm{C}, 30 \mathrm{~min}$ & $71 / 29$ & $\mathbf{1 5 a}, 55 \%$ \\
\hline \multirow[t]{2}{*}{4} & \multirow[t]{2}{*}{$\mathrm{H}(\mathbf{1 a})$} & \multirow{6}{*}{$\prod_{0}$} & \multirow[t]{2}{*}{$16 a: 16 b$} & toluene, reflux, $84 \mathrm{~h}$ & $50 / 50$ & $\mathbf{1 6 a}, 40 \%$ \\
\hline & & & & $\mathrm{MW}^{b}, 90 \mathrm{~W}, 120^{\circ} \mathrm{C}, 45 \mathrm{~min}$ & $60 / 40$ & $\mathbf{1 6 a}, 42 \%$ \\
\hline \multirow[t]{2}{*}{5} & \multirow[t]{2}{*}{$\mathrm{Cl}(\mathbf{1 b})$} & & \multirow[t]{2}{*}{$17 \mathbf{a}: 17 \mathbf{b}$} & toluene, reflux, $80 \mathrm{~h}$ & $43 / 57$ & $\mathbf{1 7 a}, 37 \%$ \\
\hline & & & & $\mathrm{MW},{ }^{b} 90 \mathrm{~W}, 120^{\circ} \mathrm{C}, 45 \mathrm{~min}$ & $76 / 24$ & $\mathbf{1 7 a}, 39 \%$ \\
\hline \multirow[t]{2}{*}{6} & \multirow[t]{2}{*}{ OMe (1c) } & & \multirow[t]{2}{*}{$18 a: 18 b$} & toluene, reflux, $54 \mathrm{~h}$ & $84 / 16$ & $\mathbf{1 8 a}, 46 \%$ \\
\hline & & & & $\mathrm{MW}^{b}{ }^{b} 120 \mathrm{~W}, 80^{\circ} \mathrm{C}, 40 \mathrm{~min}$ & $66 / 34$ & $\mathbf{1 8 a}, 30 \%$ \\
\hline 7 & $\mathrm{H}(\mathbf{1} \mathbf{a})$ & & 19a:19b & toluene, reflux, $50 \mathrm{~h}$ & $66 / 34$ & $19 a, 36 \%$ \\
\hline 8 & $\mathrm{Cl}(\mathbf{1 b})$ & & $20 a: 20 b$ & toluene, reflux, $40 \mathrm{~h}$ & $67 / 33$ & $\mathbf{2 0 b}, 21 \%$ \\
\hline 9 & OMe (1c) & & 21a:21b & toluene, reflux, $35 \mathrm{~h}$ & $65 / 35$ & $\mathbf{2 1 b}, 15 \%$ \\
\hline 10 & $\mathrm{H}(\mathbf{1 a})$ & & $22 a: 22 b$ & toluene, reflux, $48 \mathrm{~h}$ & $73 / 27$ & $\mathbf{2 2 a}, 40 \% ; \mathbf{2 2 b}, 20 \%$ \\
\hline 11 & $\mathrm{Cl}(\mathbf{1 b})$ & 0 & $23 a: 23 b$ & toluene, reflux, $41 \mathrm{~h}$ & $74 / 26$ & $\mathbf{2 3 a}, 45 \% ; \mathbf{2 3 b}, 25 \%$ \\
\hline 12 & OMe (1c) & 12 & $24 a: 24 b$ & toluene, reflux, $36 \mathrm{~h}$ & $62 / 38$ & $\mathbf{2 4 a}, 50 \% ; \mathbf{2 4 b}, 20 \%$ \\
\hline
\end{tabular}


When furan-2-carboxaldehyde (11) (Entries 7-9) and thiophene-2-carboxaldehyde (12) (Entries 1012) were similarly involved in the reactions with 2,2-dicyano-3-(4-substituted)phenyloxiranes 1a-c, ${ }^{10}$ rather similar a:b ratios were obtained, that is to say $66 / 34(\mathbf{1 9}, \mathrm{R}=\mathrm{H}), 67 / 33(\mathbf{2 0}, \mathrm{R}=\mathrm{Cl})$ and $65 / 35$ (21, $\mathrm{R}=\mathrm{OMe})$ using furan $\mathbf{1 1}$, and 73/27 (22, $\mathrm{R}=\mathrm{H}), 74 / 26(\mathbf{2 3}, \mathrm{R}=\mathrm{Cl})$ and $62 / 38(\mathbf{2 4}, \mathrm{R}=\mathrm{OMe})$ using thiophene-2-carboxaldehyde (12). The products 19a, 20b, 21b, 22a,b, 23a,b and 24a,b were isolated from the crude mixtures by column chromatography over silica gel and/or recrystallization from petrol/Et $2 \mathrm{O}$, and all the structures were first determined on the basis of ${ }^{1} \mathrm{H}$ and ${ }^{13} \mathrm{C}$ NMR chemical shifts. This was consistent with a complete NMR study including HMBC, HMQC and NOESY experiments performed on 19a. In addition, attempts to get crystals suitable for X-ray analysis from an acetone solution were successful for trans $\mathbf{2 0 b}$ and cis $\mathbf{2 4 a}$.

Reactions were finally carried out between 2,2-dicyano-3-(4-substituted)phenyloxiranes 1a-d ${ }^{10}$ and imines $25^{15}$ (1 molar equivalent) in order to get substituted 2,4-diphenyloxazolidine-5,5-dicarbonitriles (Table 3). The conversion to the derivatives 26-28 using $N$-(phenylmethylene)methanamine (25a), 3032 using $N$-(1,3-benzodioxol-5-ylmethylene)propylamine (25b), 34-36 using $N$-(1,3-benzodioxol-5ylmethylene)butylamine (25c), and 38-40 using $N$-(1,3-benzodioxol-5-ylmethylene)benzylamine (25d) were monitored by NMR, and showed that the reactions carried out in refluxing toluene were finished in 5-40 h with imines $\mathbf{2 5}$, against 35-72 h with benzaldehydes 2 . The conversion to derivatives $\mathbf{2 9}, \mathbf{3 3}$, 37 and 41 proved possible by reaction of imines 25 with 2,2-dicyano-3-(4-nitro)phenyloxirane (1d), an epoxide unable to react with benzaldehydes 2 . Also in contrast to what has been observed using aldehydes, the ${ }^{1} \mathrm{H}$ NMR spectra of the crude mixtures showed cis diastereoisomers were always mainly formed with ratios $>90 / 10$. The main compounds $\mathbf{2 6 a - 4 1 a}$ were isolated from the crude reaction mixtures by chromatography over silica gel or/and recrystallization from $\mathrm{Et}_{2} \mathrm{O}$. Yields were satisfactory for $\mathrm{R}^{1}=\mathrm{H}, \mathrm{Cl}$, OMe (48-80\%), and lower for $\mathrm{R}^{1}=\mathrm{NO}_{2}(18-40 \%)$. Even if reaction times were shorter using imines, the reactions were carried out under microwave irradiation without significant changes 
(32-85\% for $\mathrm{R}^{1}=\mathrm{H}, \mathrm{Cl}$, OMe, and $18-33 \%$ for $\mathrm{R}^{1}=\mathrm{NO}_{2}$ ). As before, recourse to NMR HMBC, HMQC and NOESY sequences allowed the assignments of ${ }^{1} \mathrm{H}$ and ${ }^{13} \mathrm{C}$ signals, as well as the detection of a correlation between $\mathrm{H} 2$ and $\mathrm{H} 4$ (see Table 3, a), in accordance with a cis stereochemistry. Cis 29a, 31a-33a and 39a were then identified unequivocally by X-ray structure analysis.

TABLE 3. Reactions between Epoxides 1 and Imines 25

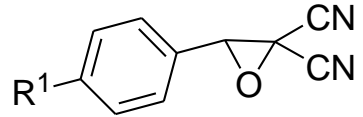

1
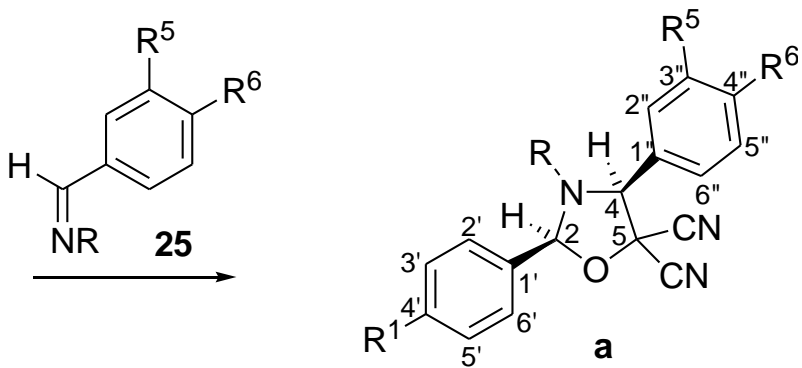

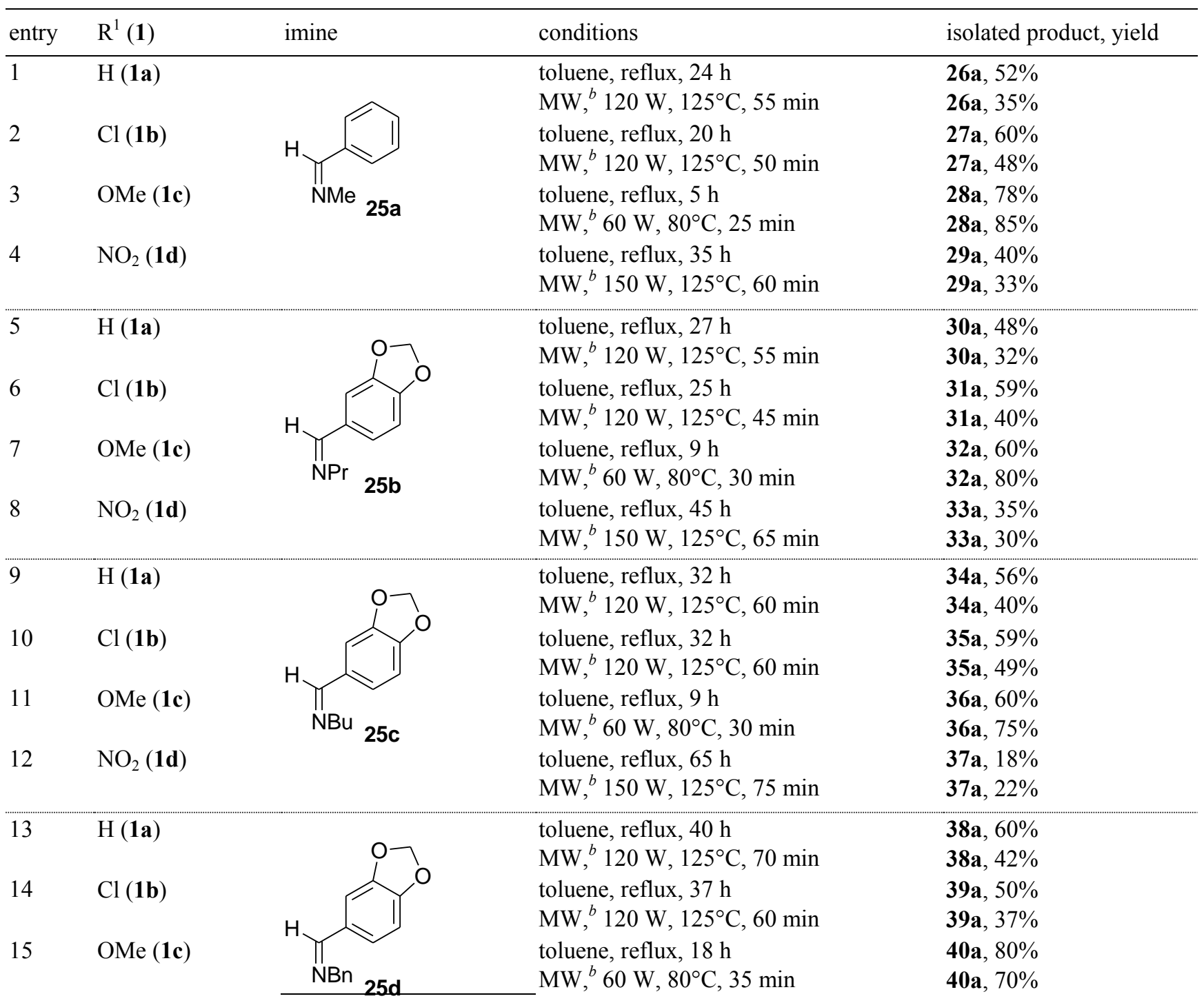


${ }^{a}$ Determined from the ${ }^{1} \mathrm{H}$ NMR spectra of the crude mixture. ${ }^{b}$ Reactions performed without solvent.

Theoretical Study of the [3+2] Cycloaddition Reactions of the Carbonyl Ylide CYa with Aldehydes and Imines

a) Analysis based on the global and local reactivity indices at the ground state of the reagents.

Recent studies devoted to Diels-Alder ${ }^{16}$ and [3+2] cycloaddition ${ }^{17}$ reactions have shown that the analysis of the global indices defined within the context of conceptual $\mathrm{DFT}^{18}$ is a powerful tool to understand the behavior of polar cycloadditions. In Table 4, we report the static global properties, namely, electronic chemical potential $\mu$, chemical hardness $\eta$, global electrophilicity $\omega$, and nucleophilicity $N$, of the carbonyl ylides CYa-c, the aromatic aldehydes 2a-c and the imines 25a and 25 e.

The electronic chemical potentials, $\mu$, of the carbonyl and imine derivatives, which range from -0.1434 to $-0.1199 \mathrm{au}$, are higher than those for the carbonyl ylides, where $\mu$ values range from -0.1576 to $-0.1746 \mathrm{au}$, indicating that along these $[3+2]$ cycloadditions the net CT will take place from the carbonyl and imine derivatives to the carbonyl ylides.

The carbonyl ylide CYa has a high electrophilicity value, ${ }^{19} \omega=4.29 \mathrm{eV}$. Electron-releasing (ER) substitution by a -OMe group decreases the electrophilicity of CYc, $\omega=3.80 \mathrm{eV}$, while electronwithdrawing (EW) substitution by a $\mathrm{Cl}$ atom increases the electrophilicity of $\mathbf{C Y b}, \omega=4.67 \mathrm{eV}$. Note that these carbonyl ylides present the larger electrophilicity of this series, indicating that along these $[3+2]$ cycloaddition reactions they will act as strong electrophiles. Unsubstituted benzaldehyde (2c) and the corresponding methyl imine 25a also have large electrophilicity values, $\omega=1.79$ and $1.32 \mathrm{eV}$, respectively, being classified as strong electrophiles within the electrophilicity scale. ${ }^{16,17}$ Substitution 
on the aromatic ring by ER -OR groups decreases the electrophilicity of the carbonyl and imine derivatives.

TABLE 4. Electronic Chemical Potential ( $\mu$, in au), Chemical Hardness ( $\eta$, in au), Global Electrophilicity $(\omega$, in eV) and Global Nucleophilicity $(N$, in $\mathrm{eV})$ values of the Carbonyl Ylides CYa-c and the Aromatic Aldehydes 2a-c and Imines 25a and 25e (by decreasing values of $\omega$ ).

\begin{tabular}{|c|c|c|c|c|c|c|}
\hline entry & compound (R) & & $\mu$ & $\eta$ & $\omega$ & $N$ \\
\hline 1 & $\mathbf{C Y b}\left(\mathrm{R}^{1}=\mathrm{Cl}\right)$ & & -0.1746 & 0.0889 & 4.67 & 3.16 \\
\hline 2 & $\mathbf{C Y a}\left(\mathrm{R}^{1}=\mathrm{H}\right)$ & & -0.1693 & 0.0908 & 4.29 & 3.28 \\
\hline 3 & CYc $\left(\mathrm{R}^{1}=\mathrm{OMe}\right)$ & $\begin{array}{ll}1 \\
\mathrm{CN}\end{array}$ & -0.1576 & 0.0890 & 3.80 & 3.62 \\
\hline 4 & $2 c\left(R^{2}=R^{3}=R^{4}=H\right)$ & & -0.1590 & 0.1923 & 1.79 & 2.18 \\
\hline 5 & 2a $\left(\mathrm{R}^{2}=\mathrm{R}^{3}=\mathrm{R}^{4}=\mathrm{OMe}\right)$ & & -0.1434 & 0.1719 & 1.63 & 2.88 \\
\hline 6 & $\mathbf{2 b}\left(\mathrm{R}^{2} \mathrm{R}^{3}=\mathrm{OCH}_{2} \mathrm{O}, \mathrm{R}^{4}=\mathrm{H}\right)$ & $\mathrm{O}^{5}$ & -0.1392 & 0.1656 & 1.59 & 3.08 \\
\hline 7 & 25a $\left(R^{5}=R^{6}=H\right)$ & & -0.1379 & 0.1964 & 1.32 & 2.70 \\
\hline 8 & 25e $\left(\mathrm{R}^{5} \mathrm{R}^{6}=\mathrm{OCH}_{2} \mathrm{O}\right)$ & $\prod^{\pi} \mathrm{NMe}$ & -0.1199 & 0.1705 & 1.15 & 3.54 \\
\hline
\end{tabular}

The carbonyl ylides have very large nucleophilicity values, ${ }^{20} N$ between 3.16 and $3.62 \mathrm{eV}$, respectively, and are also classified as strong nucleophiles. Note that the nucleophilicity is also sensitive to the substitution on the aromatic ring, the methoxy derivative CYa being the most nucleophilic species of the series given in Table 4. Interestingly, as can be concluded of the $\omega$ and $N$ values, these carbonyl ylides could act as strong electrophiles and nucleophiles in polar cycloaddition reactions. Benzaldehyde (2c) and the imine 25a have also a large nucleophilicity, which increases with the ER substitution on the phenyl ring. Thus, the imine 25e is the best nucleophile of the $\mathrm{PhCH}=\mathrm{X}(\mathrm{R})$ reagent subseries.

An analysis of the global indices indicates that both reagents involved in these [4+3] cycloadditions can act as good electrophiles and nucleophiles in polar cycloadditions. It is expected that the more favorable polar interaction will take place between the strongest electrophilic reagent and the strongest nucleophilic one. Previously, we have proposed that the better interaction will take place between the 
pairs of reagents presenting the largest $\Delta \omega,{ }^{16}$ that is, between reagents located at the opposite sides of the electrophilicity scale. In Diels-Alder reactions, we have shown that a reagent located above other reagent in the electrophilicity scale forces the last to behave as a nucleophile. ${ }^{21}$ Therefore, it is expected that in both reactions, CYa will act as the electrophile whereas $\mathbf{2 c}$ and $\mathbf{2 5 a}$ will act as nucleophiles.

Recent studies devoted to cycloaddition reactions with a polar character have shown that the analysis of the local electrophilicity index, ${ }^{22} \omega_{\mathrm{k}}$, at the electrophilic reagent and the nucleophilic Fukui function, ${ }^{23} f_{\mathrm{k}}^{-}$at the nucleophilic one allows to explain the observed regioselectivity. Very recently, we have proposed the local nucleophilicity index $N_{\mathrm{k}},{ }^{24}$ which is able to measure the local nucleophilic activation between molecules. In this way, the $\omega_{\mathrm{k}}$ and $N_{\mathrm{k}}$ at the carbonyl ylide CYa, at the aldehyde $2 \mathbf{c}$ and at the imine 25a will be used to predict the best electrophile/nucleophile interaction in these polar cycloadditions, and therefore to explain the regioselectivity experimentally observed.

The carbonyl ylide CYa has the largest electrophilic activation at the phenyl substituted $\mathrm{C} 1$ carbon atom, $\omega_{\mathrm{k}}=1.30 \mathrm{eV}$, and the largest nucleophilic activation at the dicyano-substituted $\mathrm{C} 3$ carbon atom, $N_{\mathrm{k}}=1.13 \mathrm{eV}$ (see Table 5). Therefore, $\mathrm{C} 1$ and $\mathrm{C} 3$ will be the most electrophilic and nucleophilic centers, respectively, of these carbonyl ylides. This picture is in agreement with a heterolytic $\mathrm{C} 1-\mathrm{C} 3$ bond breaking of the epoxide 1a, in which the phenyl substituted $\mathrm{C} 1$ position becomes the carbocationic center while the dicyano-substituted $\mathrm{C} 3$ position turns into the carbanionic center.

The aldehyde $2 \mathbf{c}$ has the largest electrophilic activation at the carbonyl $\mathrm{C} 4$ carbon atom, $\omega_{\mathrm{k}}=0.47$ $\mathrm{eV}$, and the largest nucleophilic activation at the carbonyl O5 oxygen atom, $N_{\mathrm{k}}=1.52 \mathrm{eV}$, whereas the imine 25a has both the largest electrophilic and nucleophilic activation sites at the imine N5 nitrogen atom, $\omega_{\mathrm{k}}=0.30 \mathrm{eV}$ and $N_{\mathrm{k}}=0.50 \mathrm{eV}$ (see Table 5). Then, while the carbonyl C4 carbon is the most electrophilic center of $\mathbf{2 c}$, the N5 nitrogen is the most electrophilic center of the imine 25a. In addition, the nucleophilic activation of the carbonyl O5 oxygen of $2 \mathbf{c}$ is three times higher than that at the imine N5 nitrogen of 25a. The results obtained for the imine 25a, which locate the most nucleophilic and 
electrophilic centers over the same atom, are a consequence of the presence of the conjugated aromatic ring at the carbon atom, which modifies the electrophilic/nucleophilic behavior of the $\mathrm{N} 5=\mathrm{C} 4$ double bond.

TABLE 5. Local Electrophilicity, $\omega_{\mathrm{k}}$, and Nucleophilicity, $N_{\mathrm{k}}$, Values (in $\mathrm{eV}$ ) of the Carbonyl Ylide CYa, Benzaldehyde (2c), and the Imine 25a

\begin{tabular}{lllll}
\hline & \multicolumn{2}{c}{$\omega_{\mathrm{k}}$} & \multicolumn{2}{c}{$N_{\mathrm{k}}$} \\
\hline CYa & $\mathrm{C} 1$ & $\mathrm{C} 3$ & $\mathrm{C} 1$ & $\mathrm{C} 3$ \\
& 1.30 & 0.45 & 0.46 & 1.13 \\
\hline $\mathbf{2 c}$ & $\mathrm{C} 4$ & O5 & C4 & O5 \\
& 0.47 & 0.35 & 0.10 & 1.52 \\
\hline $\mathbf{2 5 a}$ & C4 & N5 & C4 & N5 \\
& 0.25 & 0.30 & 0.11 & 0.50 \\
\hline
\end{tabular}

For the [3+2] cycloaddition reaction between CYa and the aldehyde 2c, the regioisomeric channels associated to the formation of the $\mathrm{C} 1-\mathrm{O} 5$ and $\mathrm{C} 3-\mathrm{C} 4$ bonds correspond to the approach that makes possible the interaction between the most electrophilic(A)/nucleophilic(B) centers of these reagents, respectively. If we consider the sum of the $\omega_{\mathrm{k}}+N_{\mathrm{k}}$ values at the two feasible interactions that take place along the CYa $+2 \mathbf{c}$ reaction, $2.82 \mathrm{eV}$ along the $\mathrm{C} 1 / \mathrm{O} 5$ two-center interaction $\left(\omega_{\mathrm{kC} 1}+N_{\mathrm{kO} 5}\right)$ and 1.60 $\mathrm{eV}\left(N_{\mathrm{kC} 3}+\omega_{\mathrm{kC} 4}\right)$ along the $\mathrm{C} 3 / \mathrm{C} 4$ two-center interaction, we can see that the former is clearly favored. This analysis allows to explain the fact that at the more favorable regioisomeric TSo1c and TSo1t, the C1-O5 bond-formation is more advanced than the $\mathrm{C} 3-\mathrm{C} 4$ one (see later).

b) Mechanistic study of the [3+2] cycloaddition reactions of the carbonyl ylide $\boldsymbol{C Y a}$ with benzaldehyde (2c) and the imine 25 .

For each one of these [3+2] cycloaddition reactions, four reactive channels have been studied. They are related to the two regioisomeric approaching modes of CYa to the aldehyde, $\mathbf{x}=\mathbf{o}$, or to the imine, $\mathbf{x}=\mathbf{n}$, named as $\mathbf{1}$ and $\mathbf{2}$, and the two stereoisomeric approaching modes related to the cis or trans rearrangement of the two phenyl substituents on the final [3+2] cycloadducts, named as c and t. Note 
that the carbonyl ylide CYa can adopt the $(E)$ or $(Z)$ configuration by the restricted rotation of the $\mathrm{C} 1$ O2 bond. While (E)-CYa adopts a planar rearrangement, ${ }^{7}(Z)-\mathbf{C Y a}$ is twisted as a consequence of the hindrance between the phenyl and one cyano group. This hindrance makes (Z)-CYa $8.6 \mathrm{kcal} / \mathrm{mol}$ higher in energy than $(E)$-CYa. In addition, the barrier height associated with the $\mathrm{C} 1-\mathrm{O} 2$ bond rotation is very large, $27.1 \mathrm{kcal} / \mathrm{mol}$. Consequently, only the $(E)$ configuration of the carbonyl ylide CYa was considered in the present study. An analysis of the stationary points associated with the reaction channels of these cycloadditions indicates that they have a one-step mechanism. Therefore, eight TSs and eight cycloadducts were located and characterized (see Scheme 2).

SCHEME 2. Reaction Channels Studied for the Cycloaddition Reaction between CYa and 2c or 25a

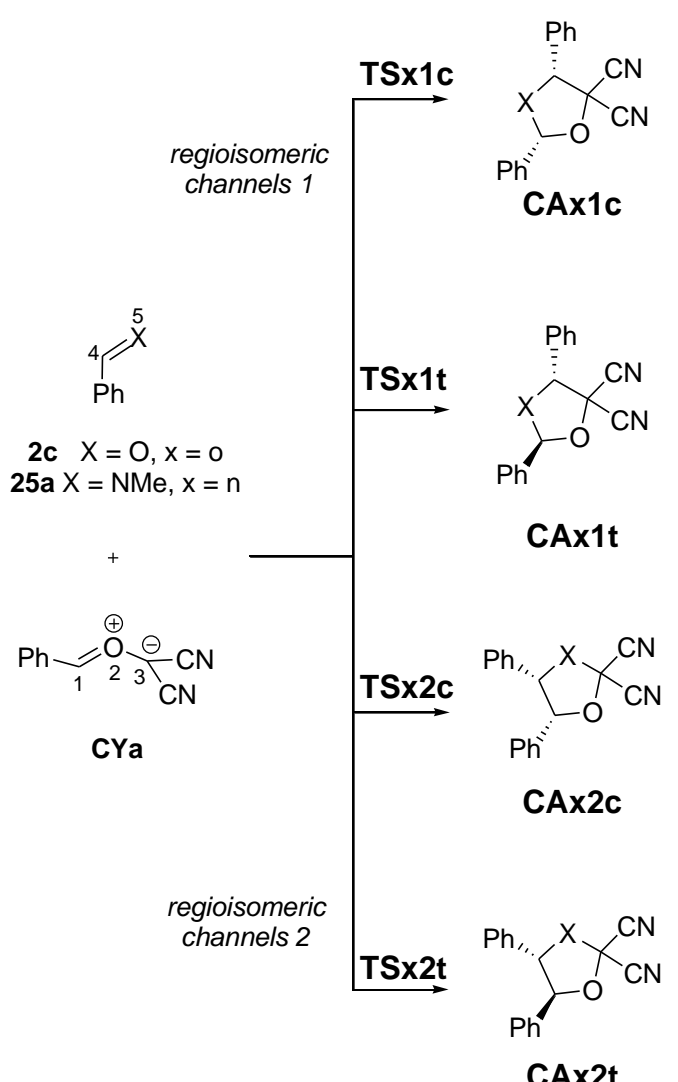

The activation energies of the most favorable reaction channels of these cycloadditions have very low values; $2.6 \mathrm{kcal} / \mathrm{mol}$ for TSo1c and $2.8 \mathrm{kcal} / \mathrm{mol}$ for TSn1t (see Table 6). The cycloadditions present a very low stereoselectivity in the case of aldehydes. For the reaction of CYa with the imine 
25a, the computed trans stereoselectivity is opposite to that found experimentally. Further single point calculations at the MP3/6-31G*//B3LYP/6-31G* yielded a trans stereoselectivity similar to that obtained at DFT level. All these [3+2] cycloaddition reactions present a total regioselectivity, being the more unfavorable regioisomeric TSs between 10 and $12 \mathrm{kcal} / \mathrm{mol}$ higher in energy. In addition, all cycloadditions are strongly exothermic: between -30.0 to $-36.0 \mathrm{kcal} / \mathrm{mol}$. These energy results are similar to those recently obtained for the [3+2] cycloaddition reaction of the carbonyl ylide CYa with $N$-methylisatin (see Scheme 1). ${ }^{7}$

TABLE 6. Total ( $E$, in au) and Relative $(\Delta E$, in $\mathrm{kcal} / \mathrm{mol})$ Energies, in Gas-Phase and in Toluene, of the Stationary Points Involved in the $[3+2]$ Cycloaddition Reactions of the Carbonyl Ylide CYa with Benzaldehyde (2c) and the Imine 25a

\begin{tabular}{|c|c|c|c|c|}
\hline & E & $\Delta \mathrm{E}$ & $\mathrm{E}_{\text {toluene }}$ & $\Delta \mathrm{E}_{\text {toluene }}$ \\
\hline CYa & -569.289033 & & -569.298872 & \\
\hline $2 c$ & -345.573442 & & -345.577940 & \\
\hline TSo1c & -914.858355 & 2.6 & -914.869424 & 4.6 \\
\hline TSo1t & -914.858333 & 2.6 & -914.869037 & 4.9 \\
\hline TSo2c & -914.841138 & 13.4 & -914.850215 & 16.7 \\
\hline TSo2t & -914.841635 & 13.1 & -914.850095 & 16.8 \\
\hline CAo1c & -914.913839 & -32.2 & -914.922338 & -28.6 \\
\hline CAo1t & -914.910561 & -30.2 & -914.918724 & -26.3 \\
\hline CAo2c & -914.904879 & -26.6 & -914.912830 & -22.6 \\
\hline CAo2t & -914.909770 & -29.7 & -914.917550 & -25.6 \\
\hline $25 a$ & -365.008701 & & -365.011670 & \\
\hline TSn1c & -934.290181 & 4.7 & -934.300925 & 6.0 \\
\hline TSn1t & -934.293307 & 2.8 & -934.304485 & 3.8 \\
\hline TSn2c & -934.274360 & 14.7 & -934.282835 & 17.4 \\
\hline TSn2t & -934.274440 & 14.6 & -934.282450 & 17.6 \\
\hline CAn1c & -934.355789 & -36.4 & -934.363842 & -33.5 \\
\hline CAn1t & -934.348124 & -31.6 & -934.356115 & -28.6 \\
\hline CAn2c & -934.350452 & -33.1 & -934.358006 & -29.8 \\
\hline CAn2t & -934.355171 & -36.0 & -934.362370 & -32.5 \\
\hline
\end{tabular}

As all these [3+2] cycloaddition reactions have a polar character and solvent can stabilize some species, solvent effects of toluene were considered through single point energy calculations over the gas-phase optimized geometries using the PCM method. Solvent effects stabilize all species between 2 and $7 \mathrm{kcal} / \mathrm{mol}$ (see Table 6), the reagents being more stabilized that the TSs. In consequence, the activation barrier for the cycloadditions increases in 2.0 and $1.0 \mathrm{kcal} / \mathrm{mol}$. In addition, solvent effects do 
not change the gas-phase low stereo- and the large regioselectivity found. Therefore, solvent effects appear to have a low influence over the [3+2] cycloaddition reactions, remaining the trans selectivity for the reaction with the imine 25a. Further thermodynamic calculations in toluene showed that TSn1t remains $2.6 \mathrm{kcal} / \mathrm{mol}$ in free energy below TSn1c (see Table 7).

Table 7. Total and Relative (Relative to TSo1t and TSn1t) Enthalpies (H, in au, and $\Delta H$, in $\mathrm{kcal} / \mathrm{mol}$ ), Entropies (S and $\Delta S$, in eu), and Free Energies $\left(\mathrm{G}\right.$, in au, and $\Delta G$, in $\mathrm{kcal} / \mathrm{mol}$ ) at $110^{\circ} \mathrm{C}$ in Toluene of the TSs Involved in the $[3+2]$ Cycloaddition Reactions of the Carbonyl Ylide CYa with Benzaldehyde (2c) and the Imine 25a.

\begin{tabular}{lllllll}
\hline & $\mathrm{H}$ & $\Delta \mathrm{H}$ & $\mathrm{S}$ & $\Delta \mathrm{S}$ & $\mathrm{G}$ & $\Delta \mathrm{G}$ \\
\hline TSo1c & -914.616511 & -0.1 & 165.36 & 1.5 & -914.717702 & -0.7 \\
TSo1t & -914.616273 & 0.0 & 163.83 & 0.0 & -914.716527 & 0.0 \\
TSn1c & -934.007402 & 2.3 & 180.64 & -0.8 & -934.117946 & 2.6 \\
TSn1t & -934.011091 & 0.0 & 181.41 & 0.0 & -934.122104 & 0.0 \\
TSn1c-Z & -934.011051 & 0.0 & 185.50 & 4.1 & -934.124567 & -1.5 \\
TSn1t-Z & -934.011018 & 0.0 & 176.33 & -5.1 & -934.118923 & 2.0 \\
\hline
\end{tabular}

One of the reviewers proposed that under the rather severe reaction conditions the imine E/Z interconversion should take place populating the less stable (Z) imine stereoisomer that is presumably a more reactive dipolarophile. In order to probe this suggestion, the TSs associated with the cis and trans approach modes of the imine 25a in the $(Z)$ configuration to the carbonyl ylide CYa, TSn1c-Z and TSn1t-Z, were optimized. However, TSn1c-Z and TSn1t-Z were located on the potential energy surface 1.0 and $1.5 \mathrm{kcal} / \mathrm{mol}$ above TSn1t (the total energies and geometries of these TSs are given is supplementary material). For the reaction of the carbonyl ylide CYa with isatin, we found that thermodynamic calculations at the reaction conditions does not modify the regio- and chemoselectivity of the reaction. In order to probe if these calculations have some incidence on the cis/trans stereochemistry of the reactions, the free energies of the TSs involved in these cycloadditions were calculated at $110^{\circ} \mathrm{C}$ in toluene. The results are summarized in Table 7 . A comparison of the free energies of the TSs involved in the cycloaddition of CYa with benzaldehyde (2c) and the imine 25a with the $(E)$ configuration indicates that the inclusion of the thermal corrections and entropy to the free energies does not modify the stereochemistry found with the gas-phase electronic energies. However, 
when the thermodynamic calculations were performed at the TSs of the imine 25a with the $(Z)$ configuration an interesting result was found. Now, TSn1c-Z is located $-1.5 \mathrm{kcal} / \mathrm{mol}$ below TSn1t in free energy, in agreement with the trans selectivity found experimentally. An analysis of the enthalpies and entropies of the TSs indicates that the large entropy associated with TSn1c-Z together with the high reaction temperature, $110^{\circ} \mathrm{C}$, are responsible for the trans selectivity.

The geometries of the TSs associated to the [3+2] cycloaddition reactions between CYa and benzaldehyde (2c) are given in Figure 1, while those associated to the reaction with the imine 25a are given in Figure 2. At the most favorable regioisomeric TSs, the lengths of the $\mathrm{C} 1-\mathrm{X} 5(\mathrm{X}=\mathrm{O}$ or $\mathrm{N})$ bonds are shorter than the $\mathrm{C} 3-\mathrm{C} 4$ ones, a similar result to that found for the reaction of CYa with $N$ methylisatin. The extent of the asynchronicity of the bond-formation in a cycloaddition reaction can be measured through the difference between the lengths of the two $\sigma$ bonds that are being formed in the reaction, i.e., $\Delta \mathrm{r}=$ dist $1-$ dist2. The asynchronicity at the TSs is 0.52 at TSo1c, 0.38 at TSo1t, 0.01 at TSo2c, 0.01 at TSo2t, 0.66 at TSn1c, 0.82 at TSn1t, 0.13 TSn2c and 0.11 at TSn2t. Two conclusions can be drawn from these values: i) the TSs associated to the more favorable regioisomeric channels 1 are far more asynchronous than those associated to the channels $\mathbf{2}$, and ii) the TSs associated to the cycloadditions involving the imine $\mathbf{2 5 a}$ are more asynchronous than those involving the aldehyde $\mathbf{2 c}$.

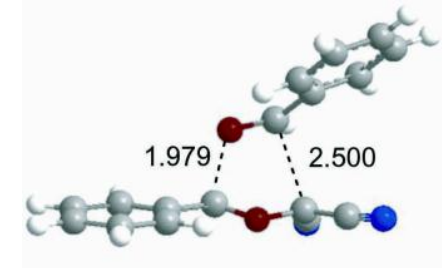

TSo1c

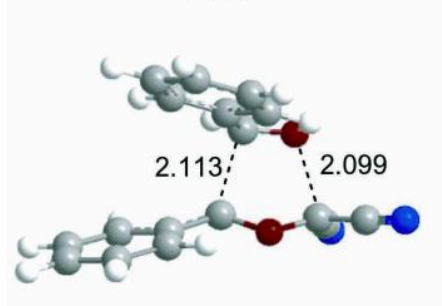

TSo2c

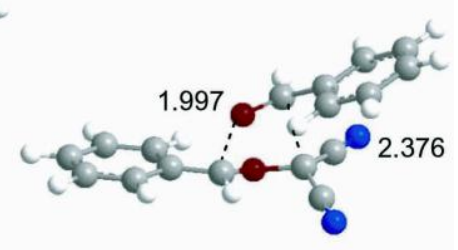

TSo1t

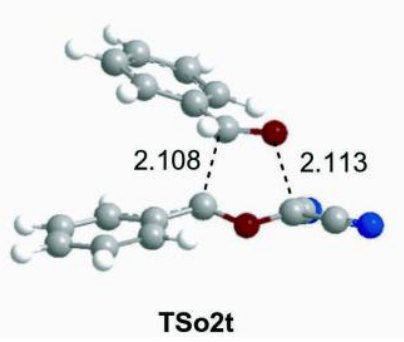


FIGURE 1. Transition Structures Involved in the Reaction of the Carbonyl Ylide CYa with

Benzaldehyde (2c)

The electronic structure of the TSs involved in the more favorable regioisomeric channels of these $[3+2]$ cycloaddition reactions was analyzed using the Wiberg bond $\operatorname{order}^{25}(\mathrm{BO})$, the natural charges obtained by a NBO (Natural Bond Order) analysis, and the topological analysis of the electron localization function (ELF). The $\mathrm{C} 1-\mathrm{X} 5(\mathrm{X}=\mathrm{O}$ or $\mathrm{N}) \mathrm{BO}$ values at the TSs are 0.32 at TSo1c, 0.32 at TSo1t, 0.40 at TSn1c and 0.34 at TSn1t, while the C3-C4 BO values are 0.20 at TSo1c, 0.24 at TSo1t, 0.14 at TSn1c and 0.01 at TSn1t. At these TSs, the C1-X5 bond formation is more advanced than the $\mathrm{C} 3-\mathrm{C} 4$ one, in clear agreement with the analysis carried out with the local electrophilicity and nucleophilicity indices. The [3+2] cycloaddition reactions involving the imine 25a are more advanced and more asynchronous than those involving the aldehyde $\mathbf{2 c}$.

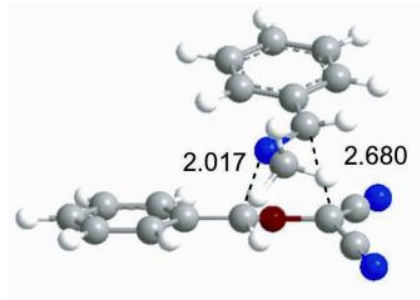

TSn1c

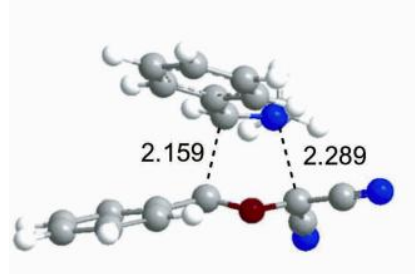

TSn2c

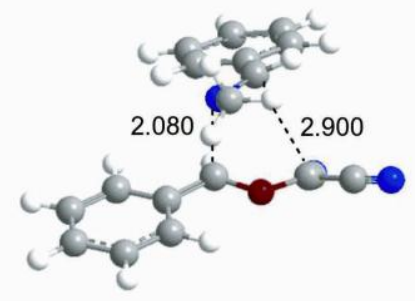

TSn1t

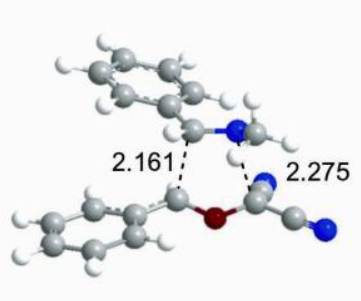

TSn2t

FIGURE 2. Transition Structures Involved in the Reaction of the Carbonyl Ylide CYa with the Imine 25a

An analysis of the atomic movement associated to the unique imaginary frequency of TSn1t indicated that it is mainly associated to the $\mathrm{C} 1-\mathrm{N} 5$ bond formation. The IRC from TSn1t to CAn1t indicates that this cycloaddition has a two-stage mechanism; ${ }^{26}$ that is, while at the first stage of the reaction only the $\mathrm{C} 1-\mathrm{N} 5$ bond is being formed, the second stage is associated to the $\mathrm{C} 3-\mathrm{C} 4$ bond 
formation. We want to remark the HPn1t structure located at the half of IRC where the C1-N5 bond formation is very advanced, $1.697 \AA$, whereas the $\mathrm{C} 3-\mathrm{C} 4$ bond formation is very delayed, $2.778 \AA$. At HPn1t, the BO values of the $\mathrm{C} 1-\mathrm{N} 5$ and C3-C4 forming-bonds are 0.74 and 0.22 , respectively. On the other hand, the IRC from the asynchronous TSo1t to CAo1t shows the concerted nature of this cycloaddition. Along the reaction, the $\mathrm{C} 1-\mathrm{O} 5$ bond-formation is slightly more advanced than the $\mathrm{C} 3-$ C4 one.

The natural population analysis (NPA) allows the evaluation of the CT and its direction at these $[3+2]$ cycloaddition reactions. The B3LYP/6-31G* natural atomic charges at the TSs associated to the most favorable regioselective channels were shared between the fragments of the carbonyl ylide CYa and the $\mathrm{PhCH}=\mathrm{X}(\mathrm{R})$ derivatives $\mathbf{2 c}$ and 25a. The net charge at the carbonyl ylide fragment at these TSs is predicted to be: $+0.03 \mathrm{e}$ at TSo1c, $+0.05 \mathrm{e}$ at TSo1t, and $-0.13 \mathrm{e}$ at TSn1c and TSn1t. Along the IRC from TSn1t to CAn1t the CT increases until it reaches $-0.20 \mathrm{e}$ at HPn1t; after this point, the CT decreases due to a back donation process from the carbonyl ylide to the imine. Some interesting conclusions can be obtained from these results: i) firstly, these values indicate that there is a change in the direction of the flux of the net CT at the TSs involving carbonyl or imine derivatives. Note that the CT obtained at the reaction of unsubstituted benzaldehyde (2c) is similar to that found in the [3+2] cycloaddition reaction of $\mathbf{C Y a}$ with $N$-methylisatin; ${ }^{7}$ ii) while at the reaction involving the imine 25a the CT increases along the first stage of the reaction until HPn1t, the unexpected low CT observed in the reaction of benzaldehyde $(\mathbf{2 c})$ remains along the reaction.

Considering that the technical details and nomenclature of the ELF topological analysis are widely available, ${ }^{27,28}$ we will concentrate our attention directly on its application ${ }^{29,30}$ to the characterization of electron delocalization and the bonding pattern associated to TSo1t and TSn1t structures. Our aim is to further elucidate the electronic nature of charge rearrangement of these TSs associated to polar cycloaddition processes. The topological analysis of ELF for both TSs reveals the same structure of attractors (Figure 3). Focusing on the valence region, disynaptic basins associated to the bonding 
regions $\mathrm{C} 4-\mathrm{X} 5, \mathrm{C} 1-\mathrm{O} 2$ and $\mathrm{O} 2-\mathrm{C} 3$ appear. In addition, monosynaptic basins associated to the $\mathrm{X} 5$, and $\mathrm{O} 2$ atom in each TS emerge. A monosynaptic basin $\mathrm{V}(\mathrm{C} 3)$ associated to the atom $\mathrm{C} 3$ of $\mathbf{C Y a}$ is also found in the reaction center of both TSs. This polarized monosynaptic basin $\mathrm{V}(\mathrm{C} 3)$ can be associated to the carbanionic center of the zwitterionic carbonyl ylide CYa. The basin populations associated to the $\mathrm{V}(\mathrm{C} 1, \mathrm{O} 2), \mathrm{V}(\mathrm{C} 3, \mathrm{O} 2)$, and $\mathrm{V}(\mathrm{C} 4, \mathrm{X} 5)$ regions are $1.84 \mathrm{e}, 1.40 \mathrm{e}$, and $1.98 \mathrm{e}$ for TSo1t and 1.81e, 1.46e, and 2.80e for TSn1t, respectively. The monosynaptic basins $\mathrm{V}(\mathrm{O} 2), \mathrm{V}(\mathrm{X} 5)$, and $\mathrm{V}(\mathrm{C} 3)$ integrate $4.27 \mathrm{e}$, 5.44e, and 1.05e in the case of TSo1t and 4.15e, 2.70e, and 0.94e in the case of TSn1t, respectively. These populations indicate a highly polarized electronic rearrangement. A complete analysis of the delocalization (not included here) reveals a greater fluctuation of electron populations between the valence basins in TSo1t than those observed in TSn1t. The electron density accumulated on the C3 center is, as noted above, higher at TSo1t than at TSn1t. This result can be rationalized by a large polarization of the former due to a back donation process (see later). The ELF topological analysis of these two TSs does not reveal disynaptic basins that can be associated to the two new forming bonds (e. g., C3-C4 and C1-X5). By considering a simple summation of electron and nuclei charges in the two separated reagent regions in both cases,${ }^{20}$ charge separations of $0.08 \mathrm{e}$ and $0.12 \mathrm{e}$ for TSo1t and TSn1t can be measured, respectively. The population analysis based on the topological regions shows that the ylide fragment is slightly positively charged in the case of TSo1t $(+0.08 \mathrm{e})$ and negatively charged in the case of TSn1t (-0.12e). These results are in complete agreement with those obtained through the NBO analysis made before. The polar nature and relative polarization of these TSs is also evident from the observed low bifurcation $\left(\eta^{*}\right)$ values occurring between the two fragments in each case. As it has been previously emphasized, ${ }^{20}$ the higher ELF bifurcation between two regions is, the higher the electron delocalization between both regions is expected. In the present case, such bifurcations are associated to the C1-X5 and C3-C4 bonding domains, $\eta_{V(C 3, C 4)}^{*}$ and $\eta_{V(C 1, X 5)}^{*}$ (See Figure 4). For TSo1t, the bifurcation values are 0.375 and 0.358 for $\mathrm{C} 1-\mathrm{X} 5$ and $\mathrm{C} 3-\mathrm{C} 4$, respectively; while for TSn1t, the corresponding values are 0.460 and 0.100 . Close bifurcation values for TSo1t can be traced out to a 
more synchronous electron charge rearrangement from $\mathrm{O} 5$ to $\mathrm{C} 1$ and from $\mathrm{C} 3$ to $\mathrm{C} 4$ (e. g., back donation as above described). This effect is absent in the attack of N5 to C1 in TSn1t. As a result, a slightly higher accumulation of charge results in the monosynaptic region associated to the carbon atom C3 in TSo1t. TSn1t becomes more polar and more asynchronous with the formation of the two new bonds.
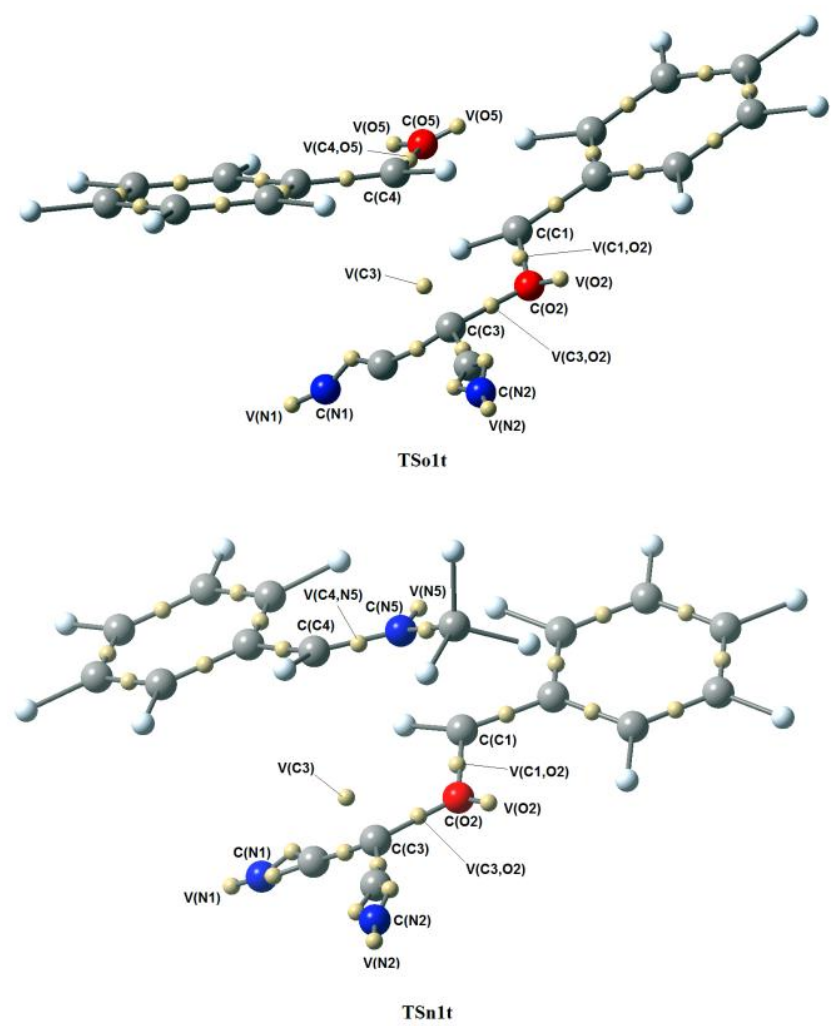

FIGURE 3. Spatial Localization of the Maxima (e. g., Attractors) of the Electron Localization Function (ELF) for TSo1t and TSn1t (only Attractors at the Reaction Center are Labeled) 

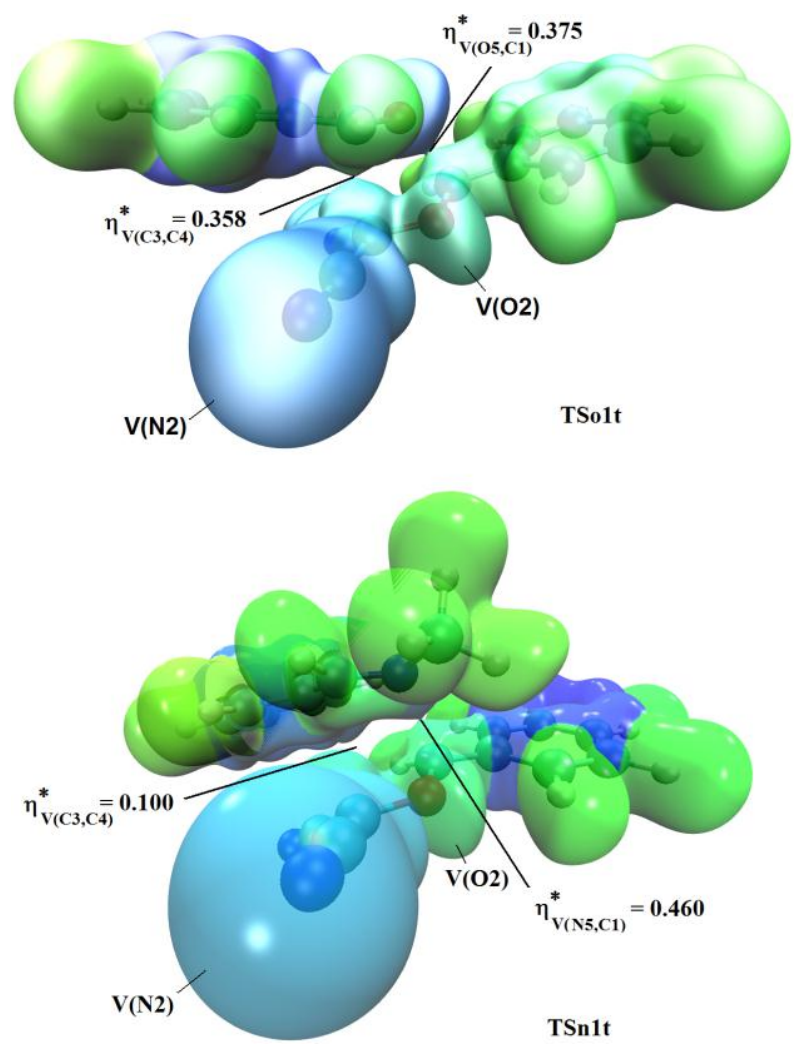

FIGURE 4. Electron Localization Function (ELF) Isosurface Pictures for TSo1t and TSn1t, Indicating the Bifurcation Values at the Region of Bond Formation. TSo1t Exhibits a More Synchronous Pattern of Delocalization at the Region of New Bond Formation than TSn1t (see Text for Details)

The ELF for HPn1t structure indicates that a disynaptic attractor can be associated to the formation of the C1-N5 bond, localizing 1.25e (see Figure 5). The monosynaptic valence attractor associated to C3 atom remains monosynaptic in nature and it integrates to $0.99 \mathrm{e}$ in HPn1t. Therefore, becomes clear that, on this pathway, the bond-formation process is more asynchronous than that for the TSo1t. This picture supports the non-concerted nature of the two-stage mechanism aforementioned: while appear a new disynaptic basin $\mathrm{V}(\mathrm{C} 1, \mathrm{~N} 5)$ indicating the formation of the $\mathrm{C} 1-\mathrm{N} 5$ bond, the monosynaptic basin $\mathrm{V}(\mathrm{C} 3)$ remains at TSn1t. $^{30 \mathrm{c}}$ The basin populations associated to the $\mathrm{V}(\mathrm{C} 1, \mathrm{O} 2), \mathrm{V}(\mathrm{C} 3, \mathrm{O} 2)$, and $\mathrm{V}(\mathrm{C} 4, \mathrm{~N} 5)$ regions are $1.46 \mathrm{e}, 1.36 \mathrm{e}$ and $2.48 \mathrm{e}$, respectively. The monosynaptic attractors $\mathrm{V}(\mathrm{O} 2), \mathrm{V}(\mathrm{N} 5)$ and $\mathrm{V}(\mathrm{C} 3)$ have populations of 4.61e, 2.00e and 0.99e. As compared to TSn1t, the HPn1t structure is in fact more polarized. The population analysis based on the topological regions indicates that the negative charge at the ylide fragment increases to $0.27 \mathrm{e}$. This result is in complete agreement with the 
NBO analysis made at HPn1t and discussed above. This fact further supports the idea that along the reaction path associated with the $\mathbf{T S n 1 t}$, the CT process is modulated by the initial attack of the N5 center to the $\mathrm{C} 1$ atom, opening the channel to the ring closure due to the attack of $\mathrm{C} 3$ atom on the ylide to the $\mathrm{C} 4$ imine center.

The present theoretical study allows one to explain the mechanism of the [3+2] cycloaddition reactions of the carbonyl ylides as CYa as well as the unexpected reverse CT found at the reactions with aldehydes and ketones. The analysis of the reactivity indices indicates that both reagents involved in these [3+2] cycloadditions (carbonyl ylides and aldehydes or imines) have electrophilic/nucleophilic behaviors. However, the large electrophilic character of the carbonyl ylides makes us to think that these intermediates will act as electrophiles in polar processes. This analysis is in clear agreement with the NBO and ELF analysis of the electronic structure of TSn1c. At this nonconcerted TS, which is associated with the nucleophilic attack of the imine N5 nitrogen to the phenyl substituted C1 carbon of the ylide, the CT fluxes clearly from the imine 25a to CYa (see Scheme 3).

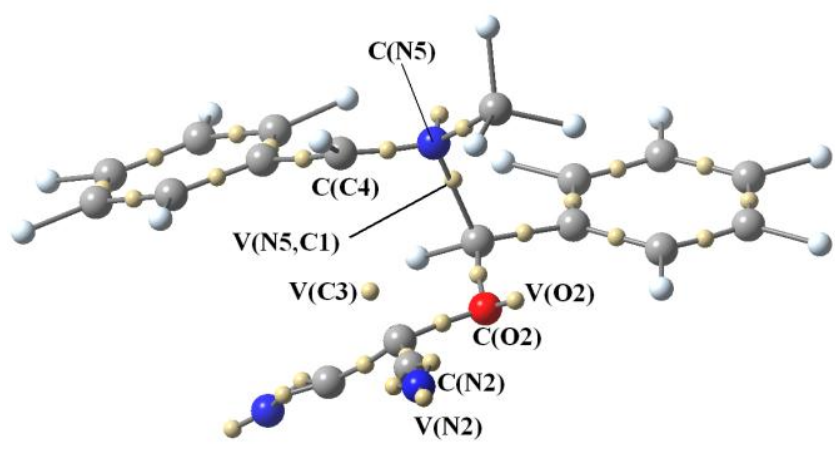

(a)

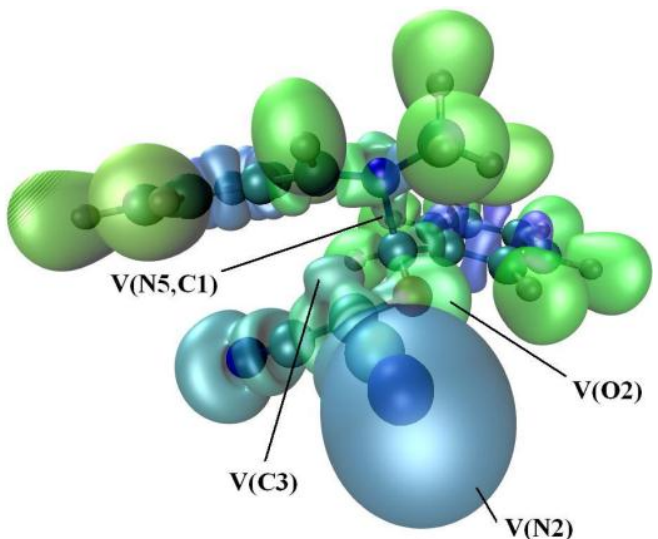

(b)

FIGURE 5. (a) Spatial Localization of the Maxima (e. g., Attractors) of the Electron Localization Function (ELF) for HPn1t Point Along the Reaction Path Associated to TSn1t. Only Attractors at the Reaction Center are Labeled. (b) ELF Isosurface $(\eta=0.728)$ Pictures for HPn1t

SCHEME 3. Flux of the CT at the TSs (the BO Values of the Forming-Bonds are Given in Bold) 


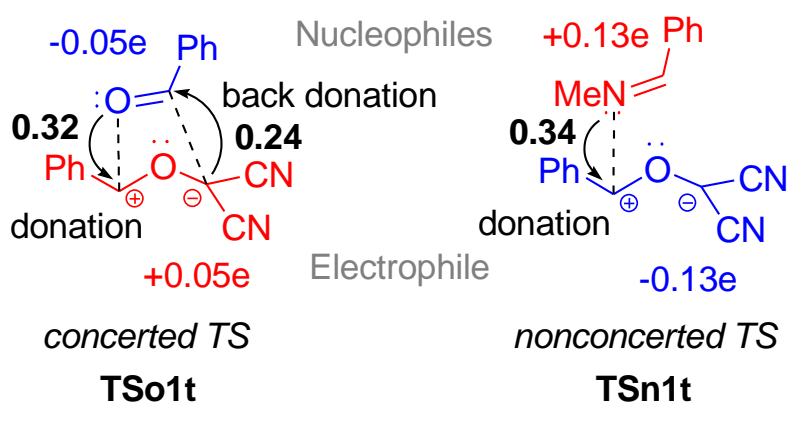

The NBO and ELF analysis of the CT at the concerted TSo1c appears to indicate that there is a change in the electrophilic/nucleophilic interaction. Now, the aldehyde $\mathbf{2 c}$ appears to act as an electrophile, being negatively charged. However, the NBO and ELF analysis of the C1-O5 and C3-C4 forming bonds at TSo1c indicates that the $\mathrm{C} 1-\mathrm{O} 5$ bond-formation is more advanced than the $\mathrm{C} 3-\mathrm{C} 4$ one. This behavior, which is in agreement with the analysis of the global and local reactivity indices, points out that the nucleophilic attack of the O5 oxygen of the aldehyde $2 \mathbf{c}$ to the electrophilically activated $\mathrm{C} 1$ center of $\mathbf{C Y a}$ is more favored than the nucleophilic attack of the $\mathrm{C} 3$ carbon of $\mathbf{C Y a}$ to the carbonyl C4 carbon of $\mathbf{2 c}$. That is, the reaction between CYa and the aldehyde $2 \mathbf{c}$ implies a nucleophilic attack of aldehyde $2 \mathbf{c}$ to CYa. But along this nucleophilic attack, the CT from the aldehyde $2 \mathbf{c}$ to CYa increases the electrophilic character of the carbonyl $\mathrm{C} 4$ carbon, favoring a concerted back donation from the nucleophilic C3 center of CYa (see ELF analysis) to the carbonyl C4 carbon. This phenomenon allows the nucleophilic attack of the aldehyde $\mathbf{2 c}$ to $\mathbf{C Y a}$ to progress and thus the whole cycloaddition process. This back donation effect balances the net CT towards the aldehyde $2 \mathbf{c}$ and allows further to explain the unexpected reverse CT found in the [3+2] cycloaddition reactions involving these strong electrophilic ylides and carbonyl compounds as dienophiles. Note that, in spite of the low CT found at TSo1t, these cycloadditions have a large polar character.

In conclusion, we have shown that first 2,5-diaryl-1,3-dioxolane-4,4-dicarbonitriles and then 2,4diphenyloxazolidine-5,5-dicarbonitriles can be prepared by regioselective cycloadditions between 
carbonyl ylides generated from epoxides. In contrast to the use of aldehydes, the reactions performed with imines proceed diastereoselectively.

The mechanism of the $[3+2]$ cycloaddition reactions of the carbonyl ylides with aldehydes and imines has been theoretically studied using DFT methods. The analysis of the reactivity indices indicates that both reagents involved in these [3+2] cycloadditions (carbonyl ylides and aldehydes or imines) have electrophilic/nucleophilic behaviors. However, the large electrophilic character of the carbonyl ylides makes them act as strong electrophiles in these polar processes. This behavior is supported by the NBO and ELF analysis of the electronic structure of TSs involved in these reactions. The cycloaddition consists of the nucleophilic attack of the aldehyde oxygen or imine nitrogen atom to the carbonyl ylide. For the reaction with aldehydes, a back donation effect that balances the net CT towards the carbonyl carbon atom allows one to explain the unexpected reverse CT found in the $[3+2]$ cycloaddition reactions involving these strong electrophilic carbonyl ylides and carbonyl compounds acting as dienophiles.

\section{Experimental Section}

General Procedure 1 for the reaction between epoxides and aldehydes using classical heating: A mixture of epoxide $(2.0 \mathrm{mmol})$ and aldehyde $(2.0 \mathrm{mmol})$ in dry toluene $(30 \mathrm{~mL})$ was heated at reflux under $\mathrm{N}_{2}$. The mixture was then evaporated to dryness and purified as specified in the product description.

General Procedure 2 for the reaction between epoxides and aldehydes using microwave

irradiation: A mixture of epoxide $(2.0 \mathrm{mmol})$ and aldehyde $(2.0 \mathrm{mmol})$ was heated in the microwave oven (power, temperature and time are given in the product description). The residue was purified as specified in the product description.

General Procedure 3 for the reaction between epoxides and imines using classical heating: A mixture of epoxide $(2.0 \mathrm{mmol})$ and imine $(2.0 \mathrm{mmol})$ in dry toluene $(30 \mathrm{~mL})$ was heated at reflux under 
$\mathrm{N}_{2}$. The mixture was then evaporated to dryness. The residue was dissolved in a minimum of $\mathrm{Et}_{2} \mathrm{O}$. Upon addition of petrol, the precipitate formed was collected by filtration before recrystallization from $\mathrm{Et}_{2} \mathrm{O}$.

General Procedure 4 for the reaction between epoxides and imines using microwave irradiation: A mixture of epoxide $(2.0 \mathrm{mmol})$ and imine $(2.0 \mathrm{mmol})$ was heated in the microwave oven (power, temperature and time are given in the product description). The residue was crystallized in $\mathrm{Et}_{2} \mathrm{O}$ /petrol 20:80 and purified as specified in the product description.

Diastereoisomers of 5-(1-naphthyl)-2-phenyl-1,3-dioxolane-4,4-dicarbonitrile (13a,b). The general procedure 1 (reflux of $80 \mathrm{~h}$ ), using 3-phenyloxirane-2,2-dicarbonitrile (1a, $0.34 \mathrm{~g})$ and 1naphthaldehyde $(9,0.31 \mathrm{~g})$, gave a 65/35 mixture from which the preponderant diastereoisomer 13a was isolated by column chromatography over silica gel (eluent: petrol/AcOEt 90:10) in 27\% yield as a white powder: $\mathrm{mp} 142^{\circ} \mathrm{C} ;{ }^{1} \mathrm{H}$ NMR $\left(\left(\mathrm{CD}_{3}\right)_{2} \mathrm{CO}\right) \delta 6.70(\mathrm{~s}, 1 \mathrm{H}), 7.07(\mathrm{~s}, 1 \mathrm{H}), 7.7(\mathrm{~m}, 8 \mathrm{H}), 8.2(\mathrm{~m}, 3 \mathrm{H})$, $8.40(\mathrm{~d}, 1 \mathrm{H}, J=8.4) ;{ }^{13} \mathrm{C} \mathrm{NMR}\left(\left(\mathrm{CD}_{3}\right)_{2} \mathrm{CO}\right) \delta 70.4,83.4,108.1,112.8,114.0,123.1,126.3,126.4$, 127.5, 127.6, 128.3, 128.5 (2C), 129.8 (2C), 130.2, 131.2, 131.8, 132.0, 134.1, 134.8; HRMS, m/z: 326.1072 found (calcd for $\mathrm{C}_{21} \mathrm{H}_{14} \mathrm{~N}_{2} \mathrm{O}_{2}, \mathrm{M}^{+\bullet}$ requires: 326.1055). The minor diastereoisomer $\mathbf{1 3 b}$ was identified by the dioxolane ring ${ }^{1} \mathrm{H}$ NMR peaks: ${ }^{1} \mathrm{H}$ NMR $\left(\left(\mathrm{CD}_{3}\right)_{2} \mathrm{CO}\right) \delta 6.98(\mathrm{~s}, 1 \mathrm{H}), 7.04(\mathrm{~s}, 1 \mathrm{H})$. The general procedure $2\left(90 \mathrm{~W}, 12 \mathrm{~min}\right.$ to reach $100^{\circ} \mathrm{C}, 16 \mathrm{~min}$ to reach $120^{\circ} \mathrm{C}$, and $40 \min$ at $\left.120^{\circ} \mathrm{C}\right)$, using 3-phenyloxirane-2,2-dicarbonitrile (1a, $0.34 \mathrm{~g})$ and 1-naphthaldehyde (9, 0.31 g), gave a 62/38 mixture from which the preponderant diastereoisomer 13a was isolated by column chromatography over silica gel (eluent: petrol/AcOEt 90:10) in 35\% yield.

\section{Diastereoisomers of 2-(4-chlorophenyl)-5-(1-naphthyl)-1,3-dioxolane-4,4-dicarbonitrile} (14a,b). The general procedure 1 (reflux of $72 \mathrm{~h}$ ), using 3-(4-chlorophenyl)oxirane-2,2-dicarbonitrile $(\mathbf{1 b}, 0.41 \mathrm{~g})$ and 1-naphthaldehyde $(9,0.31 \mathrm{~g})$, gave a 75/25 mixture from which the preponderant diastereoisomer 14a was isolated by column chromatography over silica gel (eluent: petrol/AcOEt 90:10) in $32 \%$ yield as a beige powder: $\mathrm{mp} 178^{\circ} \mathrm{C} ;{ }^{1} \mathrm{H}$ NMR $\left(\left(\mathrm{CD}_{3}\right)_{2} \mathrm{CO}\right) \delta 6.74(\mathrm{~s}, 1 \mathrm{H}), 7.09(\mathrm{~s}, 1 \mathrm{H})$, 
$7.7(\mathrm{~m}, 5 \mathrm{H}), 7.84(\mathrm{~d}, 2 \mathrm{H}, J=8.7), 8.10(\mathrm{~d}, 2 \mathrm{H}, J=7.5), 8.14(\mathrm{~d}, 1 \mathrm{H}, J=8.4), 8.37(\mathrm{~d}, 1 \mathrm{H}, J=8.4) ;{ }^{13} \mathrm{C}$ NMR $\left(\left(\mathrm{CD}_{3}\right)_{2} \mathrm{CO}\right) \delta 70.4,84.3,107.2,112.6,113.9,123.1,126.3,126.3,126.4,127.5,128.3,130.1$ (2C), 130.3 (2C), 130.3, 131.1, 131.9, 133.0, 134.8, 137.5; HRMS, $m / z: 360.0669$ found (calcd for $\mathrm{C}_{21} \mathrm{H}_{13} \mathrm{~N}_{2} \mathrm{O}_{2}{ }^{35} \mathrm{Cl}, \mathrm{M}^{+\bullet}$ requires: 360.0666 ). The minor diastereoisomer $\mathbf{1 4 b}$ was identified by the dioxolane ring ${ }^{1} \mathrm{H}$ NMR peaks: ${ }^{1} \mathrm{H}$ NMR $\left(\left(\mathrm{CD}_{3}\right)_{2} \mathrm{CO}\right) \delta 7.01(\mathrm{~s}, 1 \mathrm{H}), 7.07(\mathrm{~s}, 1 \mathrm{H})$. The general procedure $2\left(90 \mathrm{~W}, 12 \mathrm{~min}\right.$ to reach $100^{\circ} \mathrm{C}, 16 \mathrm{~min}$ to reach $120^{\circ} \mathrm{C}$, and $40 \mathrm{~min}$ at $\left.120^{\circ} \mathrm{C}\right)$, using 3-(4chlorophenyl)oxirane-2,2-dicarbonitrile $(\mathbf{1 b}, 0.41 \mathrm{~g})$ and 1-naphthaldehyde $(\mathbf{9}, 0.31 \mathrm{~g})$, gave a 63/37 mixture from which the preponderant diastereoisomer 14a was isolated by column chromatography over silica gel (eluent: petrol/AcOEt 90:10) in 42\% yield.

\section{Diastereoisomers of 2-(4-methoxyphenyl)-5-(1-naphthyl)-1,3-dioxolane-4,4-dicarbonitrile}

(15a,b). The general procedure 1 (reflux of $57 \mathrm{~h}$ ), using 3-(4-methoxyphenyl)oxirane-2,2-dicarbonitrile $(\mathbf{1 c}, 0.40 \mathrm{~g})$ and 1-naphthaldehyde $(\mathbf{9}, 0.31 \mathrm{~g})$, gave a 76/24 mixture from which the preponderant diastereoisomer 15a was isolated by column chromatography over silica gel (eluent: petrol/AcOEt 90:10) in $48 \%$ yield as a white powder: $\mathrm{mp} 155^{\circ} \mathrm{C} ;{ }^{1} \mathrm{H}$ NMR $\left(\left(\mathrm{CD}_{3}\right)_{2} \mathrm{CO}\right) \delta 3.89(\mathrm{~s}, 3 \mathrm{H}), 6.63(\mathrm{~s}, 1 \mathrm{H})$, $7.00(\mathrm{~s}, 1 \mathrm{H}), 7.14(\mathrm{~d}, 2 \mathrm{H}, J=8.7), 7.7(\mathrm{~m}, 5 \mathrm{H}), 8.1(\mathrm{~m}, 3 \mathrm{H}), 8.38(\mathrm{~d}, 1 \mathrm{H}, J=8.4) ;{ }^{13} \mathrm{C}$ NMR $\left(\left(\mathrm{CD}_{3}\right)_{2} \mathrm{CO}\right) \delta 55.8,70.1,84.1,108.3,112.9,114.2,115.2(2 \mathrm{C}), 123.2,125.9,126.3,126.4,127.4$, 127.8, 128.2, 130.2 (2C), 130.2, 131.2, 131.8, 134.8, 162.4; HRMS, $m / z$ : 356.1189 found (calcd for $\mathrm{C}_{22} \mathrm{H}_{16} \mathrm{~N}_{2} \mathrm{O}_{3}, \mathrm{M}^{+\bullet}$ requires: 356.1161 ). The minor diastereoisomer $\mathbf{1 5 b}$ was identified by the dioxolane ring ${ }^{1} \mathrm{H}$ NMR peaks: ${ }^{1} \mathrm{H}$ NMR $\left(\left(\mathrm{CD}_{3}\right)_{2} \mathrm{CO}\right) \delta 6.96(\mathrm{~s}, 1 \mathrm{H}), 6.98(\mathrm{~s}, 1 \mathrm{H})$. The general procedure $2(90 \mathrm{~W}$, $3 \mathrm{~min}$ to reach $60^{\circ} \mathrm{C}, 6 \mathrm{~min}$ to reach $80^{\circ} \mathrm{C}$, and $30 \mathrm{~min}$ at $80^{\circ} \mathrm{C}$ ), using 3-(4-methoxyphenyl)oxirane-2,2dicarbonitrile (1c, $0.40 \mathrm{~g})$ and 1-naphthaldehyde $(9,0.31 \mathrm{~g})$, gave a 71/29 mixture from which the preponderant diastereoisomer 15a was isolated by column chromatography over silica gel (eluent: petrol/AcOEt 90:10) in 55\% yield.

Diastereoisomers of 5-(indol-3-yl)-2-phenyl-1,3-dioxolane-4,4-dicarbonitrile (16a,b). The general procedure 1 (reflux of $84 \mathrm{~h}$ ), using 3-phenyloxirane-2,2-dicarbonitrile (1a, $0.34 \mathrm{~g}$ ) and indole-3- 
carboxaldehyde $(\mathbf{1 0}, 0.29 \mathrm{~g})$, gave a 50/50 mixture from which the diastereoisomer 16a was isolated by column chromatography over silica gel (eluent: petrol/AcOEt 75:25) in 40\% yield as a red powder: mp $155^{\circ} \mathrm{C} ;{ }^{1} \mathrm{H}$ NMR $\left(\left(\mathrm{CD}_{3}\right)_{2} \mathrm{CO}\right) \delta 6.43(\mathrm{~s}, 1 \mathrm{H}), 6.61(\mathrm{~s}, 1 \mathrm{H}), 7.2(\mathrm{~m}, 2 \mathrm{H}), 7.6(\mathrm{~m}, 4 \mathrm{H}), 7.8(\mathrm{~m}, 4 \mathrm{H}), 10.88$ (br s, $1 \mathrm{H}) ;{ }^{13} \mathrm{C} \mathrm{NMR}\left(\left(\mathrm{CD}_{3}\right)_{2} \mathrm{CO}\right) \delta 70.7,85.0,105.3,108.3,113.0,113.7,114.0,119.9,121.1,123.4$, 126.4, 126.4, 128.4 (2C), 129.8 (2C), 131.8, 134.7, 137.7; HRMS, m/z: 315.1035 found (calcd for $\mathrm{C}_{19} \mathrm{H}_{13} \mathrm{~N}_{3} \mathrm{O}_{2}, \mathrm{M}^{+\bullet}$ requires: 315.1008 ). The minor diastereoisomer $\mathbf{1 6 b}$ was identified by its NMR and mass spectra: ${ }^{1} \mathrm{H}$ NMR $\left(\left(\mathrm{CD}_{3}\right)_{2} \mathrm{CO}\right) \delta 6.43(\mathrm{~s}, 1 \mathrm{H}), 6.92(\mathrm{~s}, 1 \mathrm{H}), 7.22(\mathrm{t}, 1 \mathrm{H}, J=7.5), 7.29(\mathrm{t}, 1 \mathrm{H}, J=$ 7.5), $7.6(\mathrm{~m}, 4 \mathrm{H}), 7.8(\mathrm{~m}, 4 \mathrm{H}), 10.9(\mathrm{br} \mathrm{s}, 1 \mathrm{H}) ;{ }^{13} \mathrm{C} \mathrm{NMR}\left(\left(\mathrm{CD}_{3}\right)_{2} \mathrm{CO}\right) \delta 71.1,82.6,106.1,107.9,112.9$, 114.0, 114.0, 120.0, 121.0, 123.4, 126.6, 127.4, 127.5 (2C), 129.7 (2C), 131.1, 136.3, 137.7; HRMS, m/z: 315.1035 found (calcd for $\mathrm{C}_{19} \mathrm{H}_{13} \mathrm{~N}_{3} \mathrm{O}_{2}, \mathrm{M}^{+\bullet}$ requires: 315.1008$)$. The general procedure $2(90 \mathrm{~W}$, $12 \mathrm{~min}$ to reach $100^{\circ} \mathrm{C}, 16 \mathrm{~min}$ to reach $120^{\circ} \mathrm{C}$, and $45 \mathrm{~min}$ at $120^{\circ} \mathrm{C}$ ), using 3-phenyloxirane-2,2dicarbonitrile (1a, $0.34 \mathrm{~g}$ ) and indole-3-carboxaldehyde (10, 0.29 g), gave a 60/40 mixture from which the preponderant diastereoisomer 16a was isolated by column chromatography over silica gel (eluent: petrol/AcOEt 75:25) in 42\% yield.

\section{Diastereoisomers of 2-(4-chlorophenyl)-5-(indol-3-yl)-1,3-dioxolane-4,4-dicarbonitrile (17a,b).}

The general procedure 1 (reflux of 80 h), using 3-(4-chlorophenyl)oxirane-2,2-dicarbonitrile (1b, 0.41 g) and indole-3-carboxaldehyde (10, $0.29 \mathrm{~g})$, gave a 43/57 mixture from which the diastereoisomer 17a was isolated by column chromatography over silica gel (eluent: petrol/AcOEt 75:25) in 37\% yield as an orange powder: $\mathrm{mp} 200^{\circ} \mathrm{C} ;{ }^{1} \mathrm{H} \operatorname{NMR}\left(\left(\mathrm{CD}_{3}\right)_{2} \mathrm{CO}\right) \delta 6.45(\mathrm{~s}, 1 \mathrm{H}), 6.63(\mathrm{~s}, 1 \mathrm{H}), 7.21(\mathrm{t}, 1 \mathrm{H}, J=7.2), 7.29$ $(\mathrm{t}, 1 \mathrm{H}, J=7.2), 7.60(\mathrm{~d}, 1 \mathrm{H}, J=8.1), 7.66(\mathrm{~d}, 2 \mathrm{H}, J=8.5), 7.82(\mathrm{~d}, 2 \mathrm{H}, J=8.4), 7.9(\mathrm{~m}, 2 \mathrm{H}), 10.89(\mathrm{br}$ $\mathrm{s}, 1 \mathrm{H}) ;{ }^{13} \mathrm{C} \mathrm{NMR}\left(\left(\mathrm{CD}_{3}\right)_{2} \mathrm{CO}\right) \delta 70.7,85.0,105.1,107.3,113.0,113.6,113.8,119.9,121.1,123.4$, 126.3, 126.4, 130.0 (2C), 130.1 (2C), 133.6, 137.3, 137.7; HRMS, m/z: 349.0637 found (calcd for $\mathrm{C}_{19} \mathrm{H}_{12} \mathrm{~N}_{3} \mathrm{O}_{2}{ }^{35} \mathrm{Cl}, \mathrm{M}^{+\bullet}$ requires: 349.0618$)$. The diastereoisomer $\mathbf{1 7 b}$ was identified by NMR: ${ }^{1} \mathrm{H}$ NMR $\left(\left(\mathrm{CD}_{3}\right)_{2} \mathrm{CO}\right) \delta 6.44(\mathrm{~s}, 1 \mathrm{H}), 6.93(\mathrm{~s}, 1 \mathrm{H}), 7.19(\mathrm{t}, 1 \mathrm{H}, J=7.3), 7.27(\mathrm{t}, 1 \mathrm{H}, J=7.4), 7.7(\mathrm{~m}, 7 \mathrm{H}), 10.9(\mathrm{br}$ 
$\mathrm{s}, 1 \mathrm{H}) ;{ }^{13} \mathrm{C} \mathrm{NMR}\left(\left(\mathrm{CD}_{3}\right)_{2} \mathrm{CO}\right) \delta 71.1,82.6,106.0,107.0,112.8,112.9,113.9,120.0,121.0,123.4$, $126.5,126.6,129.3(2 \mathrm{C}), 129.8(2 \mathrm{C}), 135.3,136.6,137.6$. The general procedure $2(90 \mathrm{~W}, 12 \mathrm{~min}$ to reach $100^{\circ} \mathrm{C}, 16 \mathrm{~min}$ to reach $120^{\circ} \mathrm{C}$, and $45 \mathrm{~min}$ at $120^{\circ} \mathrm{C}$ ), using 3-(4-chlorophenyl)oxirane-2,2dicarbonitrile (1b, $0.41 \mathrm{~g})$ and indole-3-carboxaldehyde (10, $0.29 \mathrm{~g})$, gave a 76/24 mixture from which the preponderant diastereoisomer 17a was isolated by column chromatography over silica gel (eluent: petrol/AcOEt 75:25) in 39\% yield.

\section{Diastereoisomers of 5-(indol-3-yl)-2-(4-methoxyphenyl)-1,3-dioxolane-4,4-dicarbonitrile}

(18a,b). The general procedure 1 (reflux of 54 h), using 3-(4-methoxyphenyl)oxirane-2,2-dicarbonitrile (1c, $0.40 \mathrm{~g})$ and indole-3-carboxaldehyde (10, $0.29 \mathrm{~g})$, gave a 84/16 mixture from which the preponderant diastereoisomer 18a was isolated by column chromatography over silica gel (eluent: petrol/AcOEt $75: 25)$ in $46 \%$ yield as a greenish powder: $\mathrm{mp} 184^{\circ} \mathrm{C} ;{ }^{1} \mathrm{H}$ NMR $\left(\left(\mathrm{CD}_{3}\right)_{2} \mathrm{CO}\right) \delta 3.91(\mathrm{~s}$, $3 \mathrm{H}), 6.37(\mathrm{~s}, 1 \mathrm{H}), 6.54(\mathrm{~s}, 1 \mathrm{H}), 7.14(\mathrm{~d}, 2 \mathrm{H}, J=8.7), 7.3(\mathrm{~m}, 2 \mathrm{H}), 7.58(\mathrm{~d}, 1 \mathrm{H}, J=7.6), 7.72(\mathrm{~d}, 2 \mathrm{H}, J=$ 8.7), 7.9 (m, 2H), 10.86 (br s, $1 \mathrm{H}) ;{ }^{13} \mathrm{C} \mathrm{NMR}\left(\left(\mathrm{CD}_{3}\right)_{2} \mathrm{CO}\right) \delta 55.8,70.6,84.8,105.4,108.4,113.0,113.9$, 114.1, 115.1 (2C), 120.0, 121.0, 123.4, 126.3, 126.3, 126.5, 130.0 (2C), 137.7, 162.7; HRMS, m/z: 288.1133 found (calcd for $\mathrm{C}_{18} \mathrm{H}_{14} \mathrm{~N}_{3} \mathrm{O},[\mathrm{M}-\mathrm{H}]^{+\bullet}$ requires: 288.1133). The minor diastereoisomer $\mathbf{1 8 b}$ was identified by its ${ }^{1} \mathrm{H}$ NMR spectra selected data: ${ }^{1} \mathrm{H}$ NMR $\left(\left(\mathrm{CD}_{3}\right)_{2} \mathrm{CO}\right) \delta 3.88(\mathrm{~s}, 3 \mathrm{H}), 6.44(\mathrm{~s}, 1 \mathrm{H})$, $6.83(\mathrm{~s}, 1 \mathrm{H}), 10.8(\mathrm{br} \mathrm{s}, 1 \mathrm{H})$. The general procedure $2\left(120 \mathrm{~W}, 40 \mathrm{~min}\right.$ at $\left.80^{\circ} \mathrm{C}\right)$, using 3-(4methoxyphenyl)oxirane-2,2-dicarbonitrile (1c, $0.40 \mathrm{~g})$ and indole-3-carboxaldehyde $(\mathbf{1 0}, 0.29 \mathrm{~g})$, gave a 66/34 mixture from which the preponderant diastereoisomer 18a was isolated by column chromatography over silica gel (eluent: petrol/AcOEt 75:25) in 30\% yield.

Diastereoisomers of 5-(2-furyl)-2-phenyl-1,3-dioxolane-4,4-dicarbonitrile (19a,b). The general procedure 1 (reflux of $50 \mathrm{~h}$ ), using 3-phenyloxirane-2,2-dicarbonitrile (1a, $0.34 \mathrm{~g}$ ) and 2-furaldehyde (11, $0.39 \mathrm{~g}, 0.33 \mathrm{~mL}, 4.0 \mathrm{mmol}$ instead of $2.0 \mathrm{mmol}$ ), gave a $66 / 34$ mixture from which the preponderant diastereoisomer 19a was isolated by column chromatography over silica gel (eluent: $\mathrm{Et}_{2} \mathrm{O} /$ heptane $\left.30: 70\right)$ in $36 \%$ yield as a white powder: mp $72{ }^{\circ} \mathrm{C} ;{ }^{1} \mathrm{H}$ NMR $\left(\left(\mathrm{CD}_{3}\right)_{2} \mathrm{CO}\right) \delta 6.17(\mathrm{~s}, 1 \mathrm{H})$, 
$6.53(\mathrm{~s}, 1 \mathrm{H}), 6.64(\mathrm{dd}, 1 \mathrm{H}, J=3.4$ and 1.8), $6.99(\mathrm{~d}, 1 \mathrm{H}, J=3.4), 7.6(\mathrm{~m}, 3 \mathrm{H}), 7.7(\mathrm{~m}, 2 \mathrm{H}), 7.84(\mathrm{~d}, 1 \mathrm{H}$, $J=1.7) ;{ }^{13} \mathrm{C}$ NMR $\left(\left(\mathrm{CD}_{3}\right)_{2} \mathrm{CO}\right) \delta 68.7,82.4,108.7,112.1,112.8,113.2,113.4,128.4(2 \mathrm{C}), 129.8(2 \mathrm{C})$, 132.0, 134.0, 144.4, 146.5; HRMS, $m / z$ : 266.0690 found (calcd for $\mathrm{C}_{15} \mathrm{H}_{10} \mathrm{~N}_{2} \mathrm{O}_{3}, \mathrm{M}^{+}$requires: 266.0691). The minor diastereoisomer 19b was identified by NMR: ${ }^{1} \mathrm{H}$ NMR $\left(\left(\mathrm{CD}_{3}\right)_{2} \mathrm{CO}\right) \delta 6.47(\mathrm{~s}$, $1 \mathrm{H}), 6.62(\mathrm{dd}, 1 \mathrm{H}, J=3.2$ and 1.8), $6.81(\mathrm{~s}, 1 \mathrm{H}), 6.98(\mathrm{~d}, 1 \mathrm{H}, J=3.1), 7.5(\mathrm{~m}, 3 \mathrm{H}), 7.7(\mathrm{~m}, 2 \mathrm{H}), 7.82$ $(\mathrm{s}, 1 \mathrm{H}) ;{ }^{13} \mathrm{C} \mathrm{NMR}\left(\left(\mathrm{CD}_{3}\right)_{2} \mathrm{CO}\right) \delta 69.1,81.3,109.6,111.9,112.0,114.3,114.4,128.1(2 \mathrm{C}), 129.7(2 \mathrm{C})$, 131.7, 135.1, 146.2, 147.1.

\section{Diastereoisomers of 2-(4-chlorophenyl)-5-(2-furyl)-1,3-dioxolane-4,4-dicarbonitrile (20a,b).}

The general procedure 1 (reflux of $40 \mathrm{~h}$ ), using 3-(4-chlorophenyl)oxirane-2,2-dicarbonitrile (1b, 0.41 g) and 2-furaldehyde $(\mathbf{1 1}, 0.39 \mathrm{~g}, 0.33 \mathrm{~mL}, 4.0 \mathrm{mmol}$ instead of $2.0 \mathrm{mmol})$, gave a 67/33 mixture from which the minor diastereoisomer $\mathbf{2 0 b}$ was isolated by column chromatography over silica gel (eluent: $\mathrm{Et}_{2} \mathrm{O} /$ heptane $\left.30: 70\right)$ in $21 \%$ yield as white needles: mp $100{ }^{\circ} \mathrm{C} ;{ }^{1} \mathrm{H}$ NMR $\left(\left(\mathrm{CD}_{3}\right)_{2} \mathrm{CO}\right) \delta 6.48(\mathrm{~s}, 1 \mathrm{H})$, $6.83(\mathrm{~s}, 1 \mathrm{H}), 6.61(\mathrm{dd}, 1 \mathrm{H}, J=3.4$ and 1.9), $6.95(\mathrm{~d}, 1 \mathrm{H}, J=3.4), 7.57(\mathrm{~d}, 2 \mathrm{H}, J=8.4), 7.68(\mathrm{~d}, 2 \mathrm{H}, J=$ 8.4), $7.80(\mathrm{~d}, 1 \mathrm{H}, J=1.8) ;{ }^{13} \mathrm{C} \mathrm{NMR}\left(\left(\mathrm{CD}_{3}\right)_{2} \mathrm{CO}\right) \delta 68.9,81.3,108.7,111.9,111.9,114.3,114.4,129.9$ (2C), 129.9 (2C), 134.0, 137.2, 146.3, 146.9; HRMS, $m / z: 300.0319$ found (calcd for $\mathrm{C}_{15} \mathrm{H}_{9} \mathrm{~N}_{2} \mathrm{O}_{3}{ }^{35} \mathrm{Cl}_{\text {, }}$ $\mathrm{M}^{+\bullet}$ requires: 300.0302$)$. The preponderant diastereoisomer 20a was identified by NMR: ${ }^{1} \mathrm{H}$ NMR $\left(\left(\mathrm{CD}_{3}\right)_{2} \mathrm{CO}\right) \delta 6.17(\mathrm{~s}, 1 \mathrm{H}), 6.55(\mathrm{~s}, 1 \mathrm{H}), 6.64(\mathrm{dd}, 1 \mathrm{H}, J=3.4$ and 1.9$), 6.99(\mathrm{~d}, 1 \mathrm{H}, J=3.4), 7.59(\mathrm{~d}$, $2 \mathrm{H}, J=8.5), 7.71(\mathrm{~d}, 2 \mathrm{H}, J=8.5), 7.83(\mathrm{~d}, 1 \mathrm{H}, J=1.8) ;{ }^{13} \mathrm{C} \mathrm{NMR}\left(\left(\mathrm{CD}_{3}\right)_{2} \mathrm{CO}\right) \delta 68.5,82.2,107.5$, $111.9,112.5,112.9,113.4,129.8(2 \mathrm{C}), 129.9(2 \mathrm{C}), 132.6,137.4,144.0,146.3$.

\section{Diastereoisomers of 5-(furyl)-2-(4-methoxyphenyl)-1,3-dioxolane-4,4-dicarbonitrile (21a,b).}

The general procedure 1 (reflux of 35 h), using 3-(4-methoxyphenyl)oxirane-2,2-dicarbonitrile (1c, 0.40 g) and 2-furaldehyde $(\mathbf{1 1}, 0.39 \mathrm{~g}, 0.33 \mathrm{~mL}, 4.0 \mathrm{mmol}$ instead of $2.0 \mathrm{mmol})$, gave a 65/35 mixture from which the minor diastereoisomer 21b was isolated by column chromatography over silica gel (eluent: $\mathrm{Et}_{2} \mathrm{O} /$ heptane $\left.30: 70\right)$ in $15 \%$ yield as a beige glitter: $\mathrm{mp} 85^{\circ} \mathrm{C} ;{ }^{1} \mathrm{H} \mathrm{NMR}\left(\left(\mathrm{CD}_{3}\right)_{2} \mathrm{CO}\right) \delta 3.85(\mathrm{~s}, 3 \mathrm{H})$, 
$6.44(\mathrm{~s}, 1 \mathrm{H}), 6.60(\mathrm{dd}, 1 \mathrm{H}, J=3.3$ and 1.8), $6.74(\mathrm{~s}, 1 \mathrm{H}), 6.92(\mathrm{~d}, 1 \mathrm{H}, J=3.3), 7.05(\mathrm{~d}, 2 \mathrm{H}, J=8.8)$, $7.58(\mathrm{~d}, 2 \mathrm{H}, J=8.8), 7.59(\mathrm{~d}, 1 \mathrm{H}, J=1.8) ;{ }^{13} \mathrm{C}$ NMR $\left(\left(\mathrm{CD}_{3}\right)_{2} \mathrm{CO}\right) \delta 55.6,68.9,81.1,109.8,111.9$, 112.1, 114.2, 114.7, 115.1 (2C), 126.8, 129.9 (2C), 146.2, 147.4, 162.7; HRMS, m/z: 296.0792 found (calcd for $\mathrm{C}_{16} \mathrm{H}_{12} \mathrm{~N}_{2} \mathrm{O}_{4}, \mathrm{M}^{+\bullet}$ requires: 296.0797). The preponderant diastereoisomer 21a was identified by NMR: ${ }^{1} \mathrm{H}$ NMR $\left(\left(\mathrm{CD}_{3}\right)_{2} \mathrm{CO}\right) \delta 3.85(\mathrm{~s}, 3 \mathrm{H}), 6.11(\mathrm{~s}, 1 \mathrm{H}), 6.47(\mathrm{~s}, 1 \mathrm{H}), 6.64(\mathrm{dd}, 1 \mathrm{H}, J=3.3$ and 1.8), $6.97(\mathrm{~d}, 1 \mathrm{H}, J=3.3), 7.08(\mathrm{~d}, 2 \mathrm{H}, J=8.7), 7.61(\mathrm{~d}, 2 \mathrm{H}, J=8.7), 7.83(\mathrm{~d}, 1 \mathrm{H}, J=1.1) ;{ }^{13} \mathrm{C} \mathrm{NMR}$ $\left(\left(\mathrm{CD}_{3}\right)_{2} \mathrm{CO}\right)$ (selected data) $\delta 55.6,68.4,82.0,108.6,111.9,114.8(2 \mathrm{C}), 129.9(2 \mathrm{C}), 144.3,146.3$, 162.7 .

Diastereoisomers of 2-phenyl-5-(2-thienyl)-1,3-dioxolane-4,4-dicarbonitrile (22a,b). The general procedure 1 (reflux of $48 \mathrm{~h}$ ), using 3-phenyloxirane-2,2-dicarbonitrile (1a, $0.34 \mathrm{~g}$ ) and thiophene-2carboxaldehyde (12, $0.45 \mathrm{~g}, 0.37 \mathrm{~mL}, 4.0 \mathrm{mmol}$ instead of $2.0 \mathrm{mmol})$, gave a 73/27 mixture from which the preponderant diastereoisomer 22a was isolated by column chromatography over silica gel (eluent: $\mathrm{Et}_{2} \mathrm{O} /$ heptane 30:70) followed by recrystallization from petrol/ $\mathrm{Et}_{2} \mathrm{O} 50: 50$ in $40 \%$ yield as a white powder: $\mathrm{mp} 86^{\circ} \mathrm{C} ;{ }^{1} \mathrm{H}$ NMR $\left(\left(\mathrm{CD}_{3}\right)_{2} \mathrm{CO}\right) \delta 6.40(\mathrm{~s}, 1 \mathrm{H}), 6.56(\mathrm{~s}, 1 \mathrm{H}), 7.25(\mathrm{t}, 1 \mathrm{H}, J=4.0), 7.58(\mathrm{~s}, 4 \mathrm{H})$, 7.7 (m, 3H); ${ }^{13} \mathrm{C}$ NMR $\left(\left(\mathrm{CD}_{3}\right)_{2} \mathrm{CO}\right) \delta 70.9,85.0,108.7,112.9,113.2,128.4(2 \mathrm{C}), 128.6,129.2,129.4$, 129.8 (2C), 132.1, 132.8, 134.1; HRMS, $m / z$ : 282.0474 found (calcd for $\mathrm{C}_{15} \mathrm{H}_{10} \mathrm{~N}_{2} \mathrm{O}_{2} \mathrm{~S}, \mathrm{M}^{+\bullet}$ requires: 282.0463). The minor diastereoisomer 22b was isolated similarly in $20 \%$ yield as a greenish oil; ${ }^{1} \mathrm{H}$ NMR $\left(\left(\mathrm{CD}_{3}\right)_{2} \mathrm{CO}\right) \delta 6.47(\mathrm{~s}, 1 \mathrm{H}), 6.87(\mathrm{~s}, 1 \mathrm{H}), 7.22(\mathrm{dd}, 1 \mathrm{H}, J=5.0$ and 3.7$), 7.5(\mathrm{~m}, 4 \mathrm{H}), 7.6(\mathrm{~m}, 2 \mathrm{H})$, $7.73(\mathrm{dd}, 1 \mathrm{H}, J=5.1$ and 0.87$) ;{ }^{13} \mathrm{C} \mathrm{NMR}\left(\left(\mathrm{CD}_{3}\right)_{2} \mathrm{CO}\right) \delta 71.3,83.2,108.4,112.0,113.2,127.5(2 \mathrm{C})$, $128.4,129.4,129.8,129.7(2 \mathrm{C}), 131.4,133.7,135.5$.

\section{Diastereoisomers of 2-(4-chlorophenyl)-5-(2-thienyl)-1,3-dioxolane-4,4-dicarbonitrile (23a,b).}

The general procedure 1 (reflux of $41 \mathrm{~h}$ ), using 3-(4-chlorophenyl)oxirane-2,2-dicarbonitrile (1b, 0.41 g) and thiophene-2-carboxaldehyde (12,0.45 g, $0.37 \mathrm{~mL}, 4.0 \mathrm{mmol}$ instead of $2.0 \mathrm{mmol})$, gave a 74/26 mixture from which the preponderant diastereoisomer 23a was isolated by column chromatography 
over silica gel (eluent: $\mathrm{Et}_{2} \mathrm{O} /$ heptane 30:70) followed by recrystallization from petrol/Et ${ }_{2} \mathrm{O} 50: 50$ in $45 \%$ yield as a white powder: mp $150{ }^{\circ} \mathrm{C} ;{ }^{1} \mathrm{H}$ NMR $\left(\left(\mathrm{CD}_{3}\right)_{2} \mathrm{CO}\right) \delta 6.42(\mathrm{~s}, 1 \mathrm{H}), 6.59(\mathrm{~s}, 1 \mathrm{H}), 7.25(\mathrm{dd}$, $1 \mathrm{H}, J=5.0$ and 3.7), $7.6(\mathrm{~m}, 3 \mathrm{H}), 7.7(\mathrm{~m}, 3 \mathrm{H}) ;{ }^{13} \mathrm{C} \mathrm{NMR}\left(\left(\mathrm{CD}_{3}\right)_{2} \mathrm{CO}\right) \delta 70.7,85.0,107.7,112.8,113.0$, 128.7, 129.3, 129.5, 130.1 (2C), 130.2 (2C), 132.7, 133.0, 137.6; HRMS, m/z: 316.0068 found (calcd for $\mathrm{C}_{15} \mathrm{H}_{9} \mathrm{~N}_{2} \mathrm{O}_{2}{ }^{35} \mathrm{ClS}, \mathrm{M}^{+\bullet}$ requires: 316.0073 ). The minor diastereoisomer $\mathbf{2 3 b}$ was isolated similarly in $25 \%$ yield as a colorless oil; ${ }^{1} \mathrm{H}$ NMR $\left(\left(\mathrm{CD}_{3}\right)_{2} \mathrm{CO}\right) \delta 6.49(\mathrm{~s}, 1 \mathrm{H}), 6.90(\mathrm{~s}, 1 \mathrm{H}), 7.23(\mathrm{dd}, 1 \mathrm{H}, J=4.9$ and 3.7), $7.6(\mathrm{~m}, 3 \mathrm{H}), 7.68(\mathrm{~d}, 2 \mathrm{H}, J=8.5), 7.75(\mathrm{dd}, 1 \mathrm{H}, J=5.1$ and 0.96$) ;{ }^{13} \mathrm{C} \mathrm{NMR}\left(\left(\mathrm{CD}_{3}\right)_{2} \mathrm{CO}\right) \delta$ $71.3,83.3,107.7,111.9,113.2,128.5,129.5,130.0,129.4(2 \mathrm{C}), 129.9(2 \mathrm{C}), 133.6,134.6,136.9$.

\section{Diastereoisomers of 2-(4-methoxyphenyl)-5-(2-thienyl)-1,3-dioxolane-4,4-dicarbonitrile}

(24a,b). The general procedure 1 (reflux of 36 h), using 3-(4-methoxyphenyl)oxirane-2,2-dicarbonitrile (1c, $0.40 \mathrm{~g})$ and thiophene-2-carboxaldehyde $(\mathbf{1 2}, 0.45 \mathrm{~g}, 0.37 \mathrm{~mL}, 4.0 \mathrm{mmol}$ instead of $2.0 \mathrm{mmol})$, gave a 62/38 mixture from which the preponderant diastereoisomer $\mathbf{2 4 a}$ was isolated by column chromatography over silica gel (eluent: $\mathrm{Et}_{2} \mathrm{O} /$ heptane 30:70) followed by recrystallization from petrol/Et $\mathrm{Et}_{2} \mathrm{O} 50: 50$ in $50 \%$ yield as a pistachio powder: $\mathrm{mp} 88^{\circ} \mathrm{C} ;{ }^{1} \mathrm{H} \mathrm{NMR}\left(\left(\mathrm{CD}_{3}\right)_{2} \mathrm{CO}\right) \delta 3.85(\mathrm{~s}, 3 \mathrm{H})$, $6.32(\mathrm{~s}, 1 \mathrm{H}), 6.49(\mathrm{~s}, 1 \mathrm{H}), 7.09(\mathrm{~d}, 2 \mathrm{H}, J=8.7), 7.24(\mathrm{dd}, 1 \mathrm{H}, J=4.9$ and 3.8), $7.56(\mathrm{~d}, 1 \mathrm{H}, J=3.4)$, $7.62(\mathrm{~d}, 2 \mathrm{H}, J=8.7), 7.73(\mathrm{dd}, 1 \mathrm{H}, J=4.9$ and 0.86$) ;{ }^{13} \mathrm{C} \mathrm{NMR}\left(\left(\mathrm{CD}_{3}\right)_{2} \mathrm{CO}\right) \delta 55.7,70.7,84.7,108.7$, 112.9, 113.2, 115.0 (2C), 125.7, 128.5, 128.9, 129.2, 130.0 (2C), 132.9, 162.8; HRMS, m/z: 312.0578 found (calcd for $\mathrm{C}_{16} \mathrm{H}_{12} \mathrm{~N}_{2} \mathrm{O}_{3} \mathrm{~S}, \mathrm{M}^{+\bullet}$ requires: 312.0569). The minor diastereoisomer $\mathbf{2 4 b}$ was isolated similarly in $20 \%$ yield as colorless crystals: $\mathrm{mp} 82^{\circ} \mathrm{C} ;{ }^{1} \mathrm{H}$ NMR $\left(\left(\mathrm{CD}_{3}\right)_{2} \mathrm{CO}\right) \delta 3.86(\mathrm{~s}, 3 \mathrm{H}), 6.48(\mathrm{~s}$, $1 \mathrm{H}), 6.81(\mathrm{~s}, 1 \mathrm{H}), 7.06(\mathrm{~d}, 2 \mathrm{H}, J=8.8), 7.22(\mathrm{dd}, 1 \mathrm{H}, J=5.1$ and 3.7), $7.55(\mathrm{~d}, 1 \mathrm{H}, J=3.6), 7.59(\mathrm{~d}$, $2 \mathrm{H}, J=8.8), 7.74(\mathrm{dd}, 1 \mathrm{H}, J=5.1$ and 1.1$) ;{ }^{13} \mathrm{C} \mathrm{NMR}\left(\left(\mathrm{CD}_{3}\right)_{2} \mathrm{CO}\right) \delta 55.8,71.3,83.2,108.8,112.1$, 113.5, 115.1 (2C), 127.4, 128.5, 129.4, 129.9, 129.4 (2C), 134.1, 162.6; HRMS, m/z: 312.0575 found (calcd for $\mathrm{C}_{16} \mathrm{H}_{12} \mathrm{~N}_{2} \mathrm{O}_{3} \mathrm{~S}, \mathrm{M}^{+\bullet}$ requires: 312.0569 ).

\section{Crystallography:}


The crystals were obtained by slowly evaporating acetone solutions.

Crystal data for 5a (colorless prisms): $\mathrm{C}_{21} \mathrm{H}_{20} \mathrm{~N}_{2} \mathrm{O}_{6}, M_{\mathrm{r}}=396.39$, monoclinic, space group $P 2{ }_{1}, a=$ 7.8658(7), $b=8.6374(8), c=15.3824(16) \AA, \beta=99.533(5)^{\circ}, V=1030.65(17) \AA^{3}, Z=2, \rho_{\text {calcd }}=1.277$ g.cm ${ }^{-3}, \mu=0.095 \mathrm{~mm}^{-1}$. A final refinement on $\mathrm{F}^{2}$ with 2497 unique intensities and 262 parameters converged at $\omega \mathrm{R}\left(\mathrm{F}^{2}\right)=0.0812(\mathrm{R}(\mathrm{F})=0.0359)$ for 2359 observed reflections with $\mathrm{I}>2 \sigma(\mathrm{I})$. Crystallographic data were deposited in CSD under CCDC registration number 688228.

Crystal data for 6a (colorless prisms): $\mathrm{C}_{18} \mathrm{H}_{12} \mathrm{~N}_{2} \mathrm{O}_{4}, M_{\mathrm{r}}=320.30$, monoclinic, space group $P 2{ }_{1} / \mathrm{a}, a=$ 13.4303(7), $b=7.8903(4), c=13.9246(6) \AA, \beta=91.425(3)^{\circ}, V=1475.12(12) \AA^{3}, Z=4, \rho_{\text {calcd }}=1.442$ g.cm ${ }^{-3}, \mu=0.104 \mathrm{~mm}^{-1}$. A final refinement on $\mathrm{F}^{2}$ with 3377 unique intensities and 217 parameters converged at $\omega \mathrm{R}\left(\mathrm{F}^{2}\right)=0.0885(\mathrm{R}(\mathrm{F})=0.0391)$ for 2781 observed reflections with $\mathrm{I}>2 \sigma(\mathrm{I})$. Crystallographic data were deposited in CSD under CCDC registration number 688219.

Crystal data for $\mathbf{6 b}$ (colorless prisms): $\mathrm{C}_{18} \mathrm{H}_{12} \mathrm{~N}_{2} \mathrm{O}_{4}, M_{\mathrm{r}}=320.30$, orthorhombic, space group $P$ b c a, $a=8.2939(5), b=12.8750(6), c=27.3006(14) \AA, V=2915.3(3) \AA^{3}, Z=8, \rho_{\text {calcd }}=1.46$ g.cm ${ }^{-3}, \mu=$ $0.105 \mathrm{~mm}^{-1}$. A final refinement on $\mathrm{F}^{2}$ with 3346 unique intensities and 217 parameters converged at $\omega \mathrm{R}\left(\mathrm{F}^{2}\right)=0.1126(\mathrm{R}(\mathrm{F})=0.0471)$ for 3129 observed reflections with $\mathrm{I}>2 \sigma(\mathrm{I})$. Crystallographic data were deposited in CSD under CCDC registration number 688216.

Crystal data for 7a (colorless prisms): $\mathrm{C}_{18} \mathrm{H}_{11} \mathrm{ClN}_{2} \mathrm{O}_{4}, M_{\mathrm{r}}=354.74$, monoclinic, space group $P 2{ }_{1} / \mathrm{a}$, $a=13.7192(7), b=7.4109(4), c=15.3928(7) \AA, \beta=93.948(2)^{\circ}, V=1561.30(14) \AA^{3}, Z=4, \rho_{\text {calcd }}=$ 1.509 g.cm ${ }^{-3}, \mu=0.272 \mathrm{~mm}^{-1}$. A final refinement on $\mathrm{F}^{2}$ with 3547 unique intensities and 226 parameters converged at $\omega R\left(F^{2}\right)=0.0894(R(F)=0.0353)$ for 2987 observed reflections with $I>2 \sigma(I)$. Crystallographic data were deposited in CSD under CCDC registration number 688218.

Crystal data for 8a (colorless prisms): $\mathrm{C}_{19} \mathrm{H}_{14} \mathrm{~N}_{2} \mathrm{O}_{5}, M_{\mathrm{r}}=350.32$, monoclinic, space group $P 2{ }_{1} / \mathrm{a}, a=$ 13.9650(6), $b=7.3292(3), c=15.6911(6) \AA, \beta=95.712(2)^{\circ}, V=1598.05(11) \AA^{3}, Z=4, \rho_{\text {calcd }}=1.456$ g.cm ${ }^{-3}, \mu=0.107 \mathrm{~mm}^{-1}$. A final refinement on $\mathrm{F}^{2}$ with 3654 unique intensities and 236 parameters 
converged at $\omega \mathrm{R}\left(\mathrm{F}^{2}\right)=0.0912(\mathrm{R}(\mathrm{F})=0.0358)$ for 3085 observed reflections with $\mathrm{I}>2 \sigma(\mathrm{I})$. Crystallographic data were deposited in CSD under CCDC registration number 688223.

Crystal data for 17a (colorless prisms): $\mathrm{C}_{19} \mathrm{H}_{12} \mathrm{ClN}_{3} \mathrm{O}_{2}, M_{\mathrm{r}}=349.77$, monoclinic, space group $C 2 / \mathrm{c}$, $a=8.7943(18), b=18.422(4), c=19.814(4) \AA, \beta=92.353(9){ }^{\circ}, V=3207.3(12) \AA^{3}, Z=8, \rho_{\text {calcd }}=$ 1.449 g. $\mathrm{cm}^{-3}, \mu=0.256 \mathrm{~mm}^{-1}$. A final refinement on $\mathrm{F}^{2}$ with 3662 unique intensities and 229 parameters converged at $\omega R\left(F^{2}\right)=0.1389(R(F)=0.0525)$ for 3113 observed reflections with $\mathrm{I}>2 \sigma(\mathrm{I})$. Crystallographic data were deposited in CSD under CCDC registration number 688214.

Crystal data for $20 \mathbf{b}$ (colorless prisms): $\mathrm{C}_{15} \mathrm{H}_{9} \mathrm{ClN}_{2} \mathrm{O}_{3}, M_{\mathrm{r}}=300.69$, monoclinic, space group $P 2{ }_{1} / \mathrm{a}$, $a=5.8491(3), b=27.7737(12), c=8.3610(4) \AA, \beta=95.084(2)^{\circ}, V=1352.91(11) \AA^{3}, Z=4, \rho_{\text {calcd }}=$ $1.476 \mathrm{~g} . \mathrm{cm}^{-3}, \mu=0.294 \mathrm{~mm}^{-1}$. A final refinement on $\mathrm{F}^{2}$ with 3097 unique intensities and 190 parameters converged at $\omega R\left(F^{2}\right)=0.0955(R(F)=0.0375)$ for 2776 observed reflections with $\mathrm{I}>2 \sigma(\mathrm{I})$. Crystallographic data were deposited in CSD under CCDC registration number 688222.

Crystal data for 24a (colorless prisms): $\mathrm{C}_{16} \mathrm{H}_{12} \mathrm{~N}_{2} \mathrm{O}_{3} \mathrm{~S}, M_{\mathrm{r}}=312.34$, triclinic, space group $P-1, a=$ 8.7692(5), $b=10.0582(6), c=10.4679(6) \AA, \alpha=115.933(2), \beta=92.721(3), \gamma=112.118(2)^{\circ}, V=$ 743.87(7) $\AA^{3}, Z=2, \rho_{\text {calcd }}=1.394$ g.cm $\mathrm{cm}^{-3}, \mu=0.231 \mathrm{~mm}^{-1}$. A final refinement on $\mathrm{F}^{2}$ with 3371 unique intensities and 200 parameters converged at $\omega R\left(F^{2}\right)=0.081(R(F)=0.0315)$ for 3117 observed reflections with $\mathrm{I}>2 \sigma(\mathrm{I})$. Crystallographic data were deposited in CSD under CCDC registration number 688221.

Crystal data for 29a (colorless prisms): $\mathrm{C}_{18} \mathrm{H}_{14} \mathrm{~N}_{4} \mathrm{O}_{3}, M_{\mathrm{r}}=334.33$, monoclinic, space group $P 2{ }_{1} / \mathrm{n}, a$ $=7.2945(6), b=12.4389(12), c=18.2616(18) \AA, \beta=96.102(5)^{\circ}, V=1647.6(3) \AA^{3}, Z=4, \rho_{\text {calcd }}=$ $1.348 \mathrm{~g} . \mathrm{cm}^{-3}, \mu=0.095 \mathrm{~mm}^{-1}$. A final refinement on $\mathrm{F}^{2}$ with 3766 unique intensities and 226 parameters converged at $\omega R\left(F^{2}\right)=0.1076(R(F)=0.0431)$ for 3118 observed reflections with $\mathrm{I}>2 \sigma(\mathrm{I})$. Crystallographic data were deposited in CSD under CCDC registration number 688229. 
Crystal data for 31a (colorless plates): $\mathrm{C}_{21} \mathrm{H}_{18} \mathrm{ClN}_{3} \mathrm{O}_{3}, M_{\mathrm{r}}=395.83$, monoclinic, space group $P 2_{1}, a$ $=7.1324(9), b=7.4170(9), c=18.265(2) \AA, \beta=101.203(6)^{\circ}, V=947.8(2) \AA^{3}, Z=2, \rho_{\text {calcd }}=1.387$ g.cm ${ }^{-3}, \mu=0.229 \mathrm{~mm}^{-1}$. A final refinement on $\mathrm{F}^{2}$ with 3807 unique intensities and 255 parameters converged at $\omega \mathrm{R}\left(\mathrm{F}^{2}\right)=0.1125(\mathrm{R}(\mathrm{F})=0.049)$ for 3239 observed reflections with $\mathrm{I}>2 \sigma(\mathrm{I})$. Crystallographic data were deposited in CSD under CCDC registration number 688215.

Crystal data for 32a (yellow prisms): $\mathrm{C}_{22} \mathrm{H}_{21} \mathrm{~N}_{3} \mathrm{O}_{4}, M_{\mathrm{r}}=391.42$, orthorhombic, space group $P$ b c a, $a=11.4248(8), b=15.8816(11), c=21.3075(16) \AA, V=3866.1(5) \AA^{3}, Z=8, \rho_{\text {calcd }}=1.345$ g.cm ${ }^{-3}, \mu=$ $0.094 \mathrm{~mm}^{-1}$. A final refinement on $\mathrm{F}^{2}$ with 4413 unique intensities and 262 parameters converged at $\omega \mathrm{R}\left(\mathrm{F}^{2}\right)=0.1319(\mathrm{R}(\mathrm{F})=0.0649)$ for 3127 observed reflections with $\mathrm{I}>2 \sigma(\mathrm{I})$. Crystallographic data were deposited in CSD under CCDC registration number 688227.

Crystal data for 33a (colorless prisms): $\mathrm{C}_{21} \mathrm{H}_{18} \mathrm{~N}_{4} \mathrm{O}_{5}, M_{\mathrm{r}}=406.39$, orthorhombic, space group $P$ b c a, $a=7.0163(10), b=13.875(2), c=39.050(5) \AA, V=3801.6(9) \AA^{3}, Z=8, \rho_{\text {calcd }}=1.42$ g.cm $^{-3}, \mu=$ $0.104 \mathrm{~mm}^{-1}$. A final refinement on $\mathrm{F}^{2}$ with 4341 unique intensities and 271 parameters converged at $\omega \mathrm{R}\left(\mathrm{F}^{2}\right)=0.1123(\mathrm{R}(\mathrm{F})=0.0455)$ for 3640 observed reflections with $\mathrm{I}>2 \sigma(\mathrm{I})$. Crystallographic data were deposited in CSD under CCDC registration number 688230.

Crystal data for 39a (colorless prisms): $\mathrm{C}_{25} \mathrm{H}_{18} \mathrm{ClN}_{3} \mathrm{O}_{3}, M_{\mathrm{r}}=443.87$, monoclinic, space group $P 2{ }_{1} / \mathrm{a}$, $a=13.6352(16), b=7.6099(8), c=21.144(2) \AA, \beta=105.610(6)^{\circ}, V=2113.0(4) \AA^{3}, Z=4, \rho_{\text {calcd }}=$ 1.395 g.cm ${ }^{-3}, \mu=0.214 \mathrm{~mm}^{-1}$. A final refinement on $\mathrm{F}^{2}$ with 4809 unique intensities and 289 parameters converged at $\omega \mathrm{R}\left(\mathrm{F}^{2}\right)=0.1578(\mathrm{R}(\mathrm{F})=0.0777)$ for 4030 observed reflections with $\mathrm{I}>2 \sigma(\mathrm{I})$. Crystallographic data were deposited in CSD under CCDC registration number 688226.

\section{Computational methods:}

All calculations were carried out with the Gaussian 03 suite of programs. ${ }^{31}$ DFT calculations were carried out using the $\mathrm{B} 3 \mathrm{LYP}^{32}$ exchange-correlation functionals, together with the standard 6-31G* basis set. ${ }^{33}$ This level of theory has shown to be suitable to provide good enough performance in the 
analysis of both geometric and electronic properties in cycloaddition reactions. The stationary points were characterized by frequency calculations in order to verify that TSs had one and only one imaginary frequency. The intrinsic reaction coordinate (IRC) $)^{34}$ path was traced in order to check the energy profiles connecting each TS to the two associated minima of the proposed mechanism using the second order González-Schlegel integration method. ${ }^{35}$ The electronic structures of stationary points were analyzed by the NBO method ${ }^{36}$ and the topological analysis of the ELF, $\eta(\mathbf{r}) .^{27}$ The ELF study was performed with the TopMod program ${ }^{37}$ using the corresponding monodeterminantal wave functions of transition state structures.

Solvent effects have been considered by B3LYP/6-31G* single-point calculations on the gas phase structures using a self-consistent reaction field $(\mathrm{SCRF})^{38}$ based on the polarizable continuum model (PCM) of Tomasi's group. ${ }^{39}$ Since these reactions are carried out in toluene, we have selected its dielectric constant at $298.0 \mathrm{~K}, \varepsilon=2.38$.

The global electrophilicity index, ${ }^{19} \omega$, which measures the energy stabilization when the system acquires an additional electronic charge $\Delta N$ from the environment, is given by the following simple expression, $\omega=\left(\mu^{2} / 2 \eta\right)$, in terms of the electronic chemical potential $\mu$ and the chemical hardness $\eta$. These quantities may be approached in terms of the energies of the frontier molecular orbital HOMO and LUMO, $\varepsilon_{H}$ and $\varepsilon_{L}$, as $\mu \approx\left(\varepsilon_{H}+\varepsilon_{L}\right) / 2$ and $\eta \approx\left(\varepsilon_{L}-\varepsilon_{H}\right)$ respectively. ${ }^{40}$ Recently, we have introduced an empirical (relative) nucleophilicity index, $N$, based on the HOMO energies obtained within the Kohn-Sham scheme, and defined as $N=\varepsilon_{H O M O(N u)}-\varepsilon_{H O M O(T C E)}$, where tetracyanoethylene (TCE) is chosen as reference. ${ }^{20}$ Local electrophilicity ${ }^{22}$ and nucleophilicity ${ }^{24}$ indices, $\omega_{k}$ and $N_{k}$, were evaluated using the following expressions: $\omega_{k}=\omega f_{k}^{+}$and $N_{k}=N f_{k}^{-}$where $f_{k}^{+}$and $f_{k}^{-}$are the Fukui functions for a nucleophilic and electrophilic attacks, respectively. ${ }^{23}$ 
Acknowledgment. We are grateful to the Spanish Government (project CTQ2006-14297/BQU), the Algerian MESRS for PROFAS financial support to G. B.-A. and the Fondecyt Projects Nos. 1060961 (P. P.) and 1070378 (E. C.). E. C. and P. P. also thank the Universidad Andrés Bello (UNAB) for support through project DI 21-06/R and 45-08/R, respectively. L. R. D. also thanks the Fondecyt Grant No. 7080026 (Cooperación Internacional) for financial support and the Universidad Andrés Bello for its hospitality. We thank Jean Pierre Bazureau for generous microwave access. We thank Sourisak Sinbandhit for his contribution to this study.

Supporting Information Available: General methods, starting materials, compound characterizations, crystallography, ORTEP diagrams, copies of the ${ }^{1} \mathrm{H}$ and ${ }^{13} \mathrm{C}$ NMR spectra for compounds 13a-24a, geometries of the TSs with the (Z)-imine 25a, B3LYP/6-31G* computed total energies, unique imaginary frequencies, cartesian coordinates of the TSs and cycloadducts, and CIF files of 5a, 6a, 6b, 7a, 8a, 17a, 20b, 24a, 29a, 31a, 32a, 33a and 39a. This material is available free of charge via the Internet at http://pubs.acs.org.

\section{References and Footnotes}

(1) Huisgen, R.; Grashey, R.; Sauer, J. in The chemistry of Alkenes, Interscience: New York, 1964.

(2) (a) 1,3-Dipolar Cycloaddition Chemistry (Ed.: Padwa, A.); Wiley: New York, 1984; Vols. 1,2. (b)

Gothelf, K. V.; Jorgenson, K. A. Chem. Rev. 1998, 98, 863-909. (c) Harwood, L. M.; Vickers, R. J. in The Chemistry of Heterocyclic Compounds: Synthetic Applications of 1,3-Dipolar Cycloaddition Chemistry Toward Heterocycles and Natural Products (Eds.: Padwa, A., Pearson, W. H.); Wiley and Sons: New York, 2002.

(3) See for example : (a) Bera, S.; Malik, L.; Bhat, B.; Caroll, S. S.; Hrin, R.; MacCoss, M.; McMasters, D. R.; Miller, M. D.; Moyer, G.; Olsen, D. B.; Schleif, W. A.; Tomassini, J. E.; Eldrup, A. B. Bioorg. Med. Chem. 2004, 12, 6237-6247; (b) Liang, Y.; Narayanasamy, J.; Schinazi, R. F.; Chu, C. K. Bioorg. Med. Chem. 2006, 14, 2178-2189; (c) Wender, P. A.; Verma, V. A. Org. Lett. 2006, 8, 
1893-1896; (d) Schmidt, M.; Ungvári, J.; Glöde, J.; Dobner, B.; Langner, A. Bioorg. Med. Chem. 2007, 15, 2283-2297.

(4) See for example: (a) Tuchscherer, G.; Grell, D.; Tatsu, Y.; Durieux, P.; Fernandez-Carneado, J.; Hengst, B.; Kardinal, C.; Feller, S. Angew. Chem. Int. Ed. 2001, 40, 2844-2848; (b) Cheng, Q.; Kiyota, H.; Yamaguchi, M.; Horiguchi, T.; Oritani, T. Bioorg. Med. Chem. Lett. 2003, 13, 1075-1077; (c) Botta, M.; Armaroli, S.; Castagnolo, D.; Fontana, G.; Pera, P.; Bombardelli, E. Bioorg. Med. Chem. Lett. 2007, 17, 1579-1583; (d) Pasteris, R. J.; Hanagan, M. A.; Shapiro, R. PCT Int. Appl. 2008,294 pp, WO 2008013622 A2 20080131.

(5) (a) Robert, A.; Pommeret, J. J.; Foucaud, A. Tetrahedron Lett. 1971, 12, 231-234. (b) Robert, A.; Pommeret, J. J.; Foucaud, A. Tetrahedron 1972, 28, 2085-2097. Concerning the $\mathrm{Rh}_{2}(\mathrm{OAc})_{4}$-catalyzed synthesis of 2,5-diaryl-1,3-dioxolane, see for example: (c) Jiang, B.; Zhang, X.; Luo, Z. Org. Lett. 2002, 4, 2453-2455; (d) Russell, A. E.; Brekan, J.; Gronenberg, L.; Doyle, M. P. J. Org. Chem. 2004, 69, 5269-5274; (e) Lu, C.-D.; Chen, Z.-Y.; Liu, H.; Hu, W.-H.; Mi, A.-Q. Org. Lett. 2004, 6, 30713074.

(6) (a) Pommeret, J; J.; Robert, A. C. R. Acad. Sci. Paris, Ser. C 1971, 272, 333-336. (b) Robert, A.; Pommeret, J. J.; Marchand, E.; Foucaud, A. Tetrahedron 1973, 29, 463-468.

(7) Bentabed-Ababsa, G.; Derdour, A.; Roisnel, T.; Sáez, J. A.; Domingo, L. R.; Mongin, F. Org. Biomol. Chem. 2008, 6, 3144-3157.

(8) Sliwnska, A.; Czardybon, W.; Warkentin, J. Org. Lett. 2007, 9, 695-698.

(9) Preliminary studies have previously been reported: Bentabed, G.; Rahmouni, M.; Mongin, F.; Derdour, A.; Hamelin, J.; Bazureau, J. P. Synth. Commun. 2007, 37, 2935-2948.

(10) Baudy, M.; Robert, A.; Foucaud, A. J. Org. Chem. 1978, 43, 3732-3736.

(11) (a) de la Hoz, A.; Díaz-Ortiz, A.; Langa, F. in Microwave in Organic Synthesis (Ed.: Loupy, A.); Wiley-VCH: Weinhein, First Edition, 2002, Chapter 9. (b) Bougrin, K.; Soufiaoui, M.; Bashiardes, G. 
in Microwave in Organic Synthesis (Ed.: Loupy, A.); Wiley-VCH: Weinhein, Second Edition, 2006, Vol. 1, Chapter 11.

(12) Using a monomode reactor (Prolabo Synthewave ${ }^{\circledR} 402$ ) with accurate control of power and temperature (infrared detection).

(13) Note that the reactions did not proceed cleanly when the reactants were heated without solvent in an oil bath.

(14) Note that H5 is shifted towards high fields when a 1-naphthyl group is present at the 5 position of the dioxolane ring.

(15) Chérouvrier, J.-R.; Carreaux, F.; Bazureau, J. P. Tetrahedron Lett. 2002, 43, 3581-3584.

(16) (a) Domingo, L. R.; Aurell, M. J.; Perez, P.; Contreras, R. Tetrahedron 2002, 58, 4417-4423. (b)

Pérez, P.; Domingo, L. R.; Aizman, A.; Contreras, R. In Theoretical Aspects of Chemical Reactivity (Ed.: Toro-Labbé, A.); Elsevier Science: 2006; Vol. 19, p 167-238.

(17) Pérez, P.; Domingo, L. R.; Aurell, M. J.; Contreras, R. Tetrahedron 2003, 59, 3117-3125.

(18) (a) Geerlings, P.; De Proft, F.; Langenaeker, W. Chem. Rev. 2003, 103, 1793-1873. (b) Ess, D. H.; Jones, G. O.; Houk, K. N. Adv. Synth. Catal. 2006, 348, 2337-2361.

(19) Parr, R. G.; von Szentpaly, L.; Liu, S. J. Am. Chem. Soc. 1999, 121, 1922-1924.

(20) Domingo, L. R.; Chamorro, E.; Perez, P. J. Org. Chem. 2008, 73, 4615-4624.

(21) (a) Domingo, L. R. Eur. J. Org. Chem. 2004, 4788-4793. (b) Domingo, L. R.; Chamorro, E.; Perez. P. J. Phys. Chem. A 2008, 112, 4046-4053.

(22) Domingo, L. R.; Aurell, M. J.; Perez, P.; Contreras, R. J. Phys. Chem. A 2002, 106, 6871-6875.

(23) Parr, R. G.; Yang, W. J. Am. Chem. Soc. 1984, 106, 4049-4050.

(24) Pérez, P.; Domingo, L. R.; Duque, M.; Chamorro, E. Theochem - J. Mol. Struct. 2009, dx.doi.org/10.1016/j.theochem.2008.10.014.

(25) Wiberg, K. B. Tetrahedron 1968, 24, 1083-1096.

(26) Domingo, L. R.; Saéz, J. A.; Zaragozá, R. J.; Arnó, M. J. Org. Chem. 2008, 73, 8791-8799. 
(27) (a) Savin, A.; Becke, A. D.; Flad, J.; Nesper, R.; Preuss, H.; Vonschnering, H. G. Angew. Chem., Int. Ed. Engl. 1991, 30, 409-412. (b) Savin, A.; Silvi, B.; Colonna, F. Can. J. Chem. 1996, 74, 10881096. (c) Savin, A.; Nesper, R.; Wengert, S.; Fassler, T. F. Angew. Chem., Int. Ed. Engl. 1997, 36, 1809-1832. (d) Silvi, B. J. Mol. Struct. 2002, 614, 3-10.

(28) (a) Bader, R. F. W.; Stephens, M. E. J. Am. Chem. Soc. 1975, 97, 7391-7399. (b) Fradera, X.; Austen, M. A.; Bader R. F. W. J. Phys. Chem. A. 1999, 103, 304-314. (c) Silvi, B. Phys. Chem. Phys. 2004, 6, 256-260.

(29) (a) Chamorro, E. J. Chem. Phys. 2003, 118, 8687-8698. (b) Chamorro, E.; Notario, R. J. Chem. Phys. B. 2005, 109, 7594-7595. (c) Fuentealba, P.; Chamorro, E.; Santos, J. C. in Theoretical Aspects of Chemical Reactivity (Ed.: Toro-Labbe, A.); Elsevier, Amsterdam, 2006, Vol. 19, p. 57. (d) Chamorro, E.; Notario, R.; Santos, J. C.; Pérez, P. Chem. Phys. Lett. 2007, 443, 136-140.

(30) (a) Berski, S.; Andres, J.; Silvi, B.; Domingo, L. R. J. Phys. Chem. A 2003, 107, 6014-6024. (b) Polo, V.; Domingo, L. R.; Andres, J. J. Phys. Chem. A 2005, 109, 10438-10444. (c) Berski, S.; Andres, J.; Silvi, B.; Domingo, L. R. J. Phys. Chem. A 2006, 110, 13939-13947. (c) Polo V.; Domingo L. R; Andres J. J. Org. Chem. 2006, 71, 754-762. (d) Domingo, L. R.; Picher, M. T.; Arroyo, P.; Saez, J. A. J. Org. Chem. 2006, 71, 9319-9930.

(31) Frisch, M. J.; Trucks, G. W.; Schlegel, H. B.; Scuseria, G. E.; Robb, M. A.; Cheeseman, J. R.; Montgomery, J. J. A.; Vreven, T.; Kudin, K. N.; Burant, J. C.; Millam, J. M.; Iyengar, S. S.; Tomasi, J.; Barone, V.; Mennucci, B.; Cossi, M.; Scalmani, G.; Rega, N.; Petersson, G. A.; Nakatsuji, H.; Hada, M.; Ehara, M.; Toyota, K.; Fukuda, R.; Hasegawa, J.; Ishida, M.; Nakajima, T.; Honda, Y.; Kitao, O.; Nakai, H.; Klene, M.; Li, X.; Knox, J. E.; Hratchian, H. P.; Cross, J. B.; Adamo, C.; Jaramillo, J.; Gomperts, R.; Stratmann, R. E.; Yazyev, O.; Austin, A. J.; Cammi, R.; Pomelli, C.; Ochterski, J. W.; Ayala, P. Y.; Morokuma, K.; Voth, G. A.; Salvador, P.; Dannenberg, J. J.; Zakrzewski, V. G.; Dapprich, S.; Daniels, A. D.; Strain, M. C.; Farkas, O.; Malick, D. K.; Rabuck, A. D.; Raghavachari, K.; Foresman, J. B.; Ortiz, J. V.; Cui, Q.; Baboul, A. G.; Clifford, S.; Cioslowski, J.; Stefanov, B. B.; 
Liu, G.; Liashenko, A.; Piskorz, P.; Komaromi, I.; Martin, R. L.; Fox, D. J.; Keith, T.; Al-Laham, M. A.; Peng, C. Y.; Nanayakkara, A.; Challacombe, M.; Gill, P. M. W.; Johnson, B.; Chen, W.; Wong, M. W.; Gonzalez, C.; Pople, J. A. Gaussian03, 2004; Vol. Gaussian, Inc., Wallingford CT.

(32) (a) Becke, A. D. J. Chem. Phys. 1993, 98, 5648-5652. (b) Lee, C.; Yang, W.; Parr, R. G. Phys. Rev. B 1988, 37, 785-789.

(33) Hehre, W. J.; Radom, L.; Schleyer, P. v. R.; Pople, J. A. Ab initio Molecular Orbital Theory; Wiley: New York, 1986.

(34) Fukui, K. J. Phys. Chem. 1970, 74, 4161-4163.

(35) (a) González, C.; Schlegel, H. B. J. Phys. Chem. 1990, 94, 5523-5527. (b) González, C.; Schlegel, H. B. J. Chem. Phys. 1991, 95, 5853-5860.

(36) (a) Reed, A. E.; Curtiss, L. A.; Weinhold, F. Chem. Rev. 1988, 88, 899-926. (b) Reed, A. E.; Weinstock, R. B.; Weinhold, F. J. Chem. Phys. 1985, 83, 735-746.

(37) Noury, S.; Krokidis, X.; Fuster, F.; Silvi, B. Comput. Chem. 1999, 23, 597-604.

(38) (a) Tomasi, J.; Persico, M. Chem. Rev. 1994, 94, 2027-2094. (b) Simkin, B. Y.; Sheikhet, I. Quantum Chemical and Statistical Theory of Solutions-A Computational Approach; Ellis Horwood: London, 1995.

(39) (a) Cances, E.; Mennucci, B.; Tomasi, J. J. Chem. Phys. 1997, 107, 3032-3041. (b) Cossi, M.; Barone, V.; Cammi, R.; Tomasi, J. Chem. Phys. Lett. 1996, 255, 327-335. (c) Barone, V.; Cossi, M.; Tomasi, J. J. Comput. Chem. 1998, 19, 404-417.

(40) (a) Parr, R. G.; Pearson, R. G. J. Am. Chem. Soc. 1983, 105, 7512-7516. (b) Parr, R. G.; Yang, W. Density Functional Theory of Atoms and Molecules; Oxford University Press: New York, 1989. 